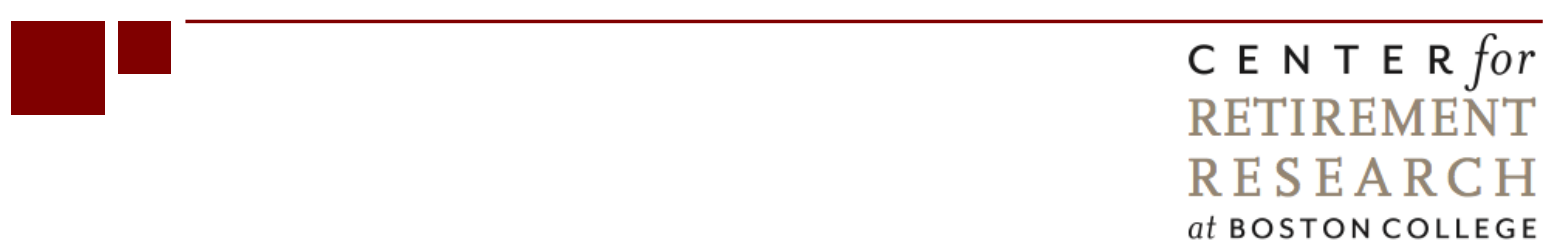

\title{
THE IMPACT OF UNEMPLOYMENT INSURANCE EXTENSIONS ON DISABILITY INSURANCE APPLICATION AND ALLOWANCE RATES
}

Matthew S. Rutledge

CRR WP 2011-17

Date Submitted: October 2011

Date Released: October 2011

Date Revised: April 2012

\author{
Center for Retirement Research at Boston College \\ Hovey House \\ 140 Commonwealth Avenue \\ Chestnut Hill, MA 02467 \\ Tel: 617-552-1762 Fax: 617-552-0191 \\ http://crr.bc.edu
}

Matthew S. Rutledge is a research economist at the Center for Retirement Research. The research reported here was performed pursuant to a grant from the U.S. Social Security Administration (SSA) funded as part of the Retirement Research Consortium (RRC). The opinions and conclusion expressed are solely those of the author and do not represent the opinions or policy of SSA, any agency of the federal government, the RRC, or Boston College.

(C) 2011, Matthew S. Rutledge. All rights reserved. Short sections of text, not to exceed two paragraphs, may be quoted without explicit permission provided that full credit, including (C) notice, is given to the source. 


\title{
About the Center for Retirement Research
}

The Center for Retirement Research at Boston College, part of a consortium that includes parallel centers at the University of Michigan and the National Bureau of Economic Research, was established in 1998 through a grant from the Social Security Administration. The Center's mission is to produce first-class research and forge a strong link between the academic community and decision-makers in the public and private sectors around an issue of critical importance to the nation's future. To achieve this mission, the Center sponsors a wide variety of research projects, transmits new findings to a broad audience, trains new scholars, and broadens access to valuable data sources.

\author{
Center for Retirement Research at Boston College \\ Hovey House \\ 140 Commonwealth Avenue \\ Chestnut Hill, MA 02467 \\ phone: 617-552-1762 fax: 617-552-0191 \\ e-mail: crr@bc.edu \\ crr.bc.edu
}

Affiliated Institutions:

The Brookings Institution

Massachusetts Institute of Technology

Syracuse University

Urban Institute 


\begin{abstract}
Both unemployment insurance (UI) extensions and the availability of disability benefits have disincentive effects on job search. But UI extensions can reduce the efficiency cost of disability benefits if UI recipients delay disability application until they exhaust their unemployment benefits. This paper, the first to focus on the effect of UI extensions on disability applications, investigates whether UI eligibility, extension, and exhaustion affect the timing of disability applications and the composition of the applicant pool. Jobless individuals are significantly less likely to apply to Social Security Disability Insurance (SSDI) during UI extensions, and significantly more likely to apply when UI is ultimately exhausted. Healthier potential applicants appear more likely to delay, as state allowance rates increase after a new UI extension. Simulations find that a 13-week UI extension decreases SSDI and Medicare costs, offsetting about half of the increase in UI payments; this suggests that the benefits of UI extensions may be understated — permanent disability benefits are diverted to shorter-run unemployment benefits and, potentially, new jobs, while easing the burden on the nearly insolvent SSDI Trust Fund.
\end{abstract}




\section{Introduction}

The Great Recession of 2007-2009 has resulted in the highest national unemployment rate in nearly 30 years, increasing from 4.7 percent to a peak of 10.1 percent, and those who find themselves unemployed remain without a job longer than ever before. Whereas the U.S. Bureau of Labor Statistics' median unemployment duration measure, which dates to 1967, had never before exceeded 12.3 weeks, the median spell remains above 20 weeks nearly four years after the financial crisis began.

In response, the federal government has extended unemployment insurance (UI) benefits up to 99 weeks, almost a year and a half longer than normal durations. In making the decision to extend benefits, policymakers must balance the need to stimulate aggregate demand and the desire to help the victims of a weak macroeconomy with the disincentive effect of additional UI benefits. The economics literature has consistently found that the job-finding rate increases significantly near the end of UI benefit duration (Moffitt 1985; Meyer 1990; Katz and Meyer 1990), suggesting that search effort has a strong influence on the probability of an unemployed worker finding a new job.

Meanwhile, the burgeoning rolls of public disability insurance programs, even before the crisis, have increased the call for disability reform (Autor and Duggan 2010), and record growth with the onset of the recession has only strengthened this effort. Social Security Disability Insurance (SSDI) applications reached an all-time high in 2010 - 2.94 million, nearly 38 percent higher than the number received in 2006 (Annual Statistical Supplement 2010). Though the purpose of public disability programs is to provide income to the long-term disabled and those with terminal conditions, numerous studies have found a positive correlation between the macroeconomy and disability applications (see Autor and Duggan 2006; and Bound and Burkhauser 1999 for literature reviews).

The extension of UI benefits, however, can ameliorate concerns about disability insurance being used as supplemental unemployment insurance. Potential disability applicants may delay their application until they have exhausted their extended UI benefits. In the meantime, costs are transferred from the SSDI Trust Fund, scheduled to be exhausted in 2018 (Social Security Trustees Report 2011), to general revenue, which is more fungible. In addition, some delayed applicants might find jobs, thereby reducing the long-term costs of the disability programs. 
This paper investigates whether the availability of unemployment insurance, in general, and extended UI benefits, in particular, delays disability applications and changes the composition of the pool of remaining applicants. This study uses the variation in the total UI duration provided by extensions to estimate whether remaining UI eligibility, extension, and exhaustion affect individual workers' hazard to SSDI application, using the Survey of Income and Program Participation (SIPP) Gold Standard File, which links job loss data from a household survey to disability application and earnings information from the SSA's administrative records. The effect of a new UI extension on the proportion of a state's workers who apply to the SSDI program and the (lagged) success rate for these applications provide corroborating evidence on the incentive to apply for disability and the composition of applicants.

The results indicate that jobless individuals are significantly less likely to apply for disability benefits during the months their UI benefits are extended and significantly more likely to apply to SSDI in the month that UI is ultimately exhausted. State-level analysis suggests that relatively healthier applicants are most likely to delay application during the first months of a UI extension, thereby increasing the allowance rate observed after the applications wind their way through the determination process.

A simulation then uses these results to calculate the change in expected costs to the UI, SSDI, and Medicare systems of a 13- or 26-week UI extension. Based on individual-specific benefits and the predicted probability of applying to SSDI successfully or unsuccessfully, or finding re-employment, these simulations indicate that UI extensions reduce the expected cost of SSDI and Medicare benefits, offsetting about half of the increase in the cost of UI benefits. The cost savings suggests that the benefits of UI extensions may be understated.

These results are consistent with growing evidence that the definition of a work-limiting disability, far from an objective, context-free state, depends on the availability (Autor and Duggan 2003) and generosity (Lindner 2011) of alternative sources of income available to potential disability beneficiaries. This paper suggests, however, that other efficiency gains, due to the diversion of some recipients of permanent, expensive benefits into shorter-term benefits and, potentially, jobs, offset some of the efficiency loss of the job-finding disincentives.

The next section discusses the existing literature on the relationship between job search and both unemployment insurance and disability insurance. Section 3 describes the details of unemployment insurance and public disability programs. Section 4 sketches a conceptual model 
for how UI eligibility and exhaustion may affect disability application. Section 5 describes the data. Section 6 outlines the empirical models for both the individual- and state-level regressions, as well as the cost simulation. Section 7 discusses the results, and Section 8 concludes.

\section{Previous Literature}

The idea that job finding rates increase substantially near the end of an individual's unemployment benefit eligibility is well-established both in theoretical models (Mortensen 1977, Moffitt and Nicholson 1982) and in empirical studies. Moffitt (1985) was the first study to use duration-model analysis to examine the distribution of unemployment spells, finding spikes at 26 and 39 weeks, consistent with two standard UI benefit durations. Meyer (1990) and Katz and Meyer (1990) find more direct evidence that UI exit rates are highly correlated with benefit duration and that UI extensions lead some workers to delay their return to work.

Still, most empirical estimates of the effect of UI extensions on the length of unemployment spells find only moderate positive relationships. The estimated effect of a oneweek increase in the duration of UI benefits ranges from 0.08 (Card and Levine 2000) to 0.20 (Katz and Meyer 1990). ${ }^{1}$ Elsby, Hobijn, and Sahin (2010) suggest that estimates on the lower end are more appropriate for more recent extensions, as workers in the recessions of the 1970's and 1980's were more likely to be recalled after temporary layoffs than the modern-day unemployed. They also suggest that estimates of the disincentive effect of UI on job search may be overestimated, as UI is extended most often in slack local labor market conditions, so durations may be longer around the time of UI extensions not because of UI but because of the inability for the jobless to find work. ${ }^{2}$ Indeed, Card and Levine (2000), which uses an exogenous UI extension in New Jersey during the mid-1990's expansion, estimate the smallest response to UI duration. It is also well-established that increases in the unemployment rate are associated with increases in disability applications (Stapleton et al. 1998; Rupp and Scott 1998; Black, Daniel, and Sanders 2002; Autor and Duggan 2003). On a micro level, a few papers have used a Moffitt-Meyer-style duration model to estimate the effect of unemployment insurance on

\footnotetext{
${ }^{1}$ These estimates focus on the average duration of nonemployment, but more heterogeneous impacts are possible. Gritz and MaCurdy (1997) find very little response in the median nonemployment duration to UI extensions, but longer spells of nonemployment get even longer when UI benefits are extended.

${ }^{2}$ Jurajda and Tannery (2003) find a larger spike in job finding rates in Philadelphia, which survived the 1980's recession relatively intact, than in Pittsburgh, where unemployment rates soared. However, they find little statistically significant difference between the job-finding hazard among workers in the two cities once they account for the interaction of unemployment rate with remaining UI duration.
} 
the probability of applying for disability insurance but only with data from outside the United States; Roed and Zhang (2005) and Henningsen (2007) use Norwegian data, Larsson (2006) uses Swedish data, and Pellizzari (2006) samples households in six European countries. These papers all find a significant increase in the hazard to disability-insurance application or receipt in the months approaching UI exhaustion.

For U.S. data, only Lindner (2011) examines the association between applying for SSDI and SSI and the generosity of UI benefits on a micro-level. He similarly estimates a hazard model of disability application using SIPP data linked to SSA administrative records, but his focus is on estimating the elasticity of DI application with respect to the UI monthly benefit amount. Because of this different focus, Lindner includes measures of the maximum spell duration in the individual's state and whether the benefits were ever extended instead of more direct controls for the UI duration facing the specific individual. Lindner also limits his analysis to the individual decision to apply for DI and to take up UI, without considering the effect of UI policy on the composition, and eventual success, of DI applicants. He finds that higher UI benefits significantly reduce the hazard into the DI program, but he can discern no coherent pattern in the elasticity of DI application with respect to UI generosity by the ordinal month of the jobless spell.

Other studies have focused on the composition of the applicant pool and their eventual success in obtaining disability benefits. Strand (2002), in a comprehensive analysis of the determinants of SSDI and SSI initial allowance rates, finds that a 1-percentage-point increase in the state unemployment rate is associated with a 1.3- to 1.9-percentage-point decline in the allowance rate. Rupp and Stapleton (1995) find a negative correlation between the initial allowance rate and the unemployment rate lagged by one and two years but not the current unemployment rate, as expected. Autor and Duggan (2003) model the decision to apply for disability benefits "conditionally,” where the individual chooses to apply only in the event of a job loss, which motivates their finding that selection bias has helped lower the observed unemployment rate as more high school dropouts shift to the disability rolls. This paper estimates whether conditional applicants are further induced by unemployment insurance eligibility changes within their jobless spell, conditional on local labor market conditions.

This paper is the first to focus on the effect of UI extensions on disability applications and the applicant pool. It contributes to the literature that estimates the effect of UI duration and 
extension on exit from unemployment by exploring the importance of an additional exit pathway. It provides another estimate of the effect of macroeconomic conditions on both the state-level application rate and the individual decision to apply for disability. Finally, this paper extends the literature on how macroeconomic conditions affect the SSDI and SSI allowance rates both at the state-level and by individuals’ eventual success in obtaining disability benefits.

\section{Institutional Background}

Unemployment Insurance. Most workers who lose their jobs involuntarily and without cause, or voluntarily quit in some states depending on the reason, are eligible for unemployment benefits. The system is financed mostly through taxes on employers that are experience-rated, where employers that have a history of former employees collecting benefits often are taxed at a higher rate. Although states must meet criteria to be eligible for federally financed administrative costs, the parameters of the unemployment system vary greatly by state, including the payroll tax level and experience rating, the weekly benefit formula, the formula for determining the duration of benefits, and the automatic triggers for extended benefits. The U.S. Department of Labor's Employment and Training Administration collects these details in the “Comparison of State Unemployment Insurance Laws” annual report.

Unemployed workers' eligibility depends on their accumulated earnings exceeding a proscribed level during the base period, which for most states is the first four out of the last five completed calendar quarters. The weekly benefit amount is then a certain percentage, usually between $1 / 24$ and 1/26, of the worker's earnings in the highest-earning quarter (27 states) or the average of their best two quarters (11 states) during the base period. As there are 13 weeks in a quarter, the replacement rate, or the ratio of the weekly benefit amount to the pre-job loss weekly wage, is roughly 50 percent, though the replacement rate is less than one-half for higher wage workers, because most states cap the weekly benefit amount at a fraction (most often two-thirds) of the state's average weekly wage. Twelve states then add a small stipend for each dependent child, up to a maximum. The weekly benefit levels vary greatly between the states; Massachusetts has the highest maximum benefit (\$625 in 2011) and Washington the highest minimum benefit (\$135), while Mississippi has by far the lowest maximum benefit $(\$ 235$, with a minimum of \$30 per week). 
The duration of benefits is either set at a fixed level for all UI recipients (nine states), or depends on the total amount of benefits unemployed workers can receive during their eligibility period. This "maximum entitlement" is the lesser of 26 (or 30 in Massachusetts) times the weekly benefit amount or a fraction, usually one-third (16 states), of total base period earnings. The benefit duration is then the maximum entitlement divided by the weekly benefit amount. For most people, this calculation results in 26 (or 30) weeks exactly, but durations may be shorter for individuals whose base period earnings are concentrated in just one or two calendar quarters. $^{3}$

There are two ways in which UI benefits may be extended. One is through federal emergency legislation, including laws passed in 1991, 2002, and 2008 that extended benefits nationwide, with funding from the federal government's general revenue. The Emergency Unemployment Compensation Act of 1991 initially added 13 weeks of benefits, and later 26 weeks, to normal durations for all states, though states could qualify for longer extensions (20 weeks initially, and later 33 weeks) if the unemployment rate was sufficiently high. The Temporary Extended Unemployment Compensation Act of 2002 added 50 percent to normal durations (up to 13 weeks), while making automatic state triggers easier to hit, with the federal government financing the difference. Finally, the Emergency Unemployment Compensation Program of 2008 initially added 20 weeks, plus an additional 13 weeks if the state unemployment rate was sufficiently high; after October 2009, all states received 34 weeks (Tiers 1 and 2), plus another 13 (Tier 3) to 19 weeks (Tier 4) if the state unemployment rate exceeded certain levels.

The other extension route is the Extended Benefits program. This program is triggered by high and rising unemployment rates, based on standards imposed by federal law. All states must extend UI durations by 13 weeks during these periods, but states may opt for additional triggers, which provide an additional 13 to 33 weeks. ${ }^{4}$ When benefits are extended

\footnotetext{
${ }^{3}$ Alaska, Idaho, Montana, North Carolina, and North Dakota use a sliding scale based on the ratio of base period earnings to the highest quarter's earnings to calculate duration. For example, Montana has a maximum duration of 28 weeks, longer than all but one other state, but workers must have a ratio of 3.5 or better, essentially ruling out any worker with volatile quarterly earnings or short recent work history. In addition, New Jersey and Pennsylvania base duration on the number of accumulated "credit weeks," weeks where earnings exceeded a small threshold.

${ }^{4}$ The mandatory extension is 13 weeks when the 13-week rolling average of the insured unemployment rate is at least 5 percent and is 120 percent of the average insured unemployment rate over the same period each of the previous two years. (The insured unemployment rate, or IUR, is the number of individuals receiving UI benefits after the first week divided by the number of workers eligible for or already receiving UI.) The first optional level adds 13 weeks if the IUR averages at least 6 percent for 13 weeks, regardless of past rates; 39 states participate in
} 
automatically, the federal government pays for one-half of the added cost. The federal emergency extensions of 2002 and 2008 supplemented the automatic Extended Benefits program, while the federal extension in 1991 superseded the state-level triggers (Whittaker and Isaacs 2011).

UI duration varies across states and individuals and over time: the adjustment in the duration formula for workers with highly concentrated earnings over their base period; the longer durations in Massachusetts (30 weeks for 1989 to present), Montana (28 weeks for 2004 to present), and Washington (30 weeks for 1989 to 2004); automatically triggered Extended Benefits; and federal emergency extensions. Figure 1 plots the histograms of durations in the regression sample from the SIPP Gold Standard File for those whose benefits were and were not never during their time between job loss and either disability application, re-employment, or censoring. Not surprisingly, the plurality of jobless individuals are eligible for 26 weeks of unemployment benefits, but more than 81 percent of the sample is eligible for a different number of weeks, including 76 percent of those unaffected by a UI extension (including those whose benefits were already extended before the job loss).

Disability Insurance. The SSA administers two programs that provide disability benefits to qualified workers. Workers with work-limiting health conditions and a sufficient amount of total and recent working experience may qualify for SSDI. Those with lower incomes may qualify for SSI. Many work-limited, low-income individuals with sufficient work experience apply to both programs concurrently.

An individual is SSDI-insured if he or she has accumulated a sufficient number of "work credits," both over his or her career and over the last 10 years. A worker earns one work credit for every \$1,120 earned in 2011, up to four credits a year (which are meant to represent the number of calendar quarters worked, but without necessitating quarterly reporting). Individuals need to earn two credits per year since the year they turned 21, with 20 of those credits (for those age 31 and older) coming in the last 10 years

this program. The second optional level adds another 13 weeks if the three-month rolling average of the more familiar total unemployment rate is at least 6.5 percent and is 110 percent of the rolling average in either of the previous two years, or 20 weeks if the unemployment rate is 8 percent with the same comparison to previous years; 11 states participated in this level in 2009, but that increased to 38 states in 2010. 
Individuals who are not working can apply for disability beginning five months after the onset of the disability. The Disability Determination Service in the applicant's state uses information from medical providers to decide whether the individual's medical condition is sufficiently severe and on the List of Impairments, whether the applicant can do the same work he or she did before, and whether he or she can do any other type of work. Approximately 37 percent of applications are allowed at the initial determination, according to the data used in the state-level regression, but some states have consistently higher or lower allowance rates across years, even accounting for observable differences between the states (Strand 2002).

The SSDI benefit is calculated from the same Primary Insurance Amount (PIA) formula as Social Security old-age retirement benefits. The PIA is a graduated percentage of a worker's Average Indexed Monthly Earnings, which are the average earnings over the individual's working years (excluding up to the five lowest-earning years), adjusted for the growth of overall wages in each year. ${ }^{5}$ In addition, SSDI beneficiaries are eligible for health insurance coverage through Medicare 24 months after first being entitled to benefits.

Few applicants leave SSDI before their Full Retirement Age (FRA), when their benefits are rolled into the old-age retirement program. About 7.6 percent of exits can be attributed to SSDI recipients being found no longer medically eligible in a Continuing Disability Review (Annual Statistical Supplement 2010). In addition, recipients who earn more than a set amount for a sufficient number of months may be removed from the SSDI rolls. ${ }^{6}$

Working-age individuals are eligible for SSI only if their income and wealth fall below eligibility thresholds and they satisfy a similar disability screening to SSDI. Countable income, which includes one’s own and one’s spouse’s income but excludes \$20 per month of non-labor income and, for workers, \$65 per month plus one-half of labor earnings beyond this level, must be below the federal SSI benefit level. In addition, non-housing wealth (excluding automobiles, life insurance, burial plots, and burial funds) must be below $\$ 2,000$. The individual can then receive the difference between the monthly benefit level of $\$ 674$ and the recipient’s countable income.

\footnotetext{
${ }^{5}$ The PIA formula can be found in Section 7 of the Social Security Handbook (http://www.ssa.gov/OP_Home/handbook/ssa-hbk.htm).

${ }^{6}$ SSDI beneficiaries can earn up to $\$ 720$ (in 2011) in any of nine months over a 5-year period as part of the Trial Work Period. After the ninth month, the beneficiary moves into an Extended Period of Eligibility for three years; benefits are not paid in a month if earnings exceed the Substantial Gainful Activity level (\$1,000 in 2011) in that month, except for the first time, which allows for a three-month grace period.
} 
There are no restrictions on SSDI or SSI applicants receiving unemployment benefits, so individuals may apply for both unemployment and disability benefits at the same time. In fact, UI benefits can help to bridge the gap between SSDI application and the first receipt of benefits. Disability recipients, however, are excluded from UI benefits in most states because they are no longer able and available to work, but nine states exempt those who are unavailable because of illness or disability from the "able and available” requirement provided they do not refuse suitable work offers.

\section{Conceptual Framework}

This study provides a simple model of the decision by utility-maximizing individuals who have recently experienced a job loss to either apply for disability insurance or search for a job (and thereby receive UI benefits, if the current time is before UI exhaustion). ${ }^{7}$ The individuals' utility in month $\mathrm{t}, V_{t}$, is simply the larger of the utility from disability application, $V_{t}^{d}$, and the utility from job search, $V_{t}^{s}$.

The utility from job search depends on the unemployment benefits, $b$, which are received when the current time $t$ is before the exhaustion point $L$; the probability of finding a job, $\mathrm{p}$; the discount factor $\beta$; the wage offer $w$, which is always accepted and earned in every period until infinity with no risk of further job loss; and the continuation value $V_{t+1}$ :

$$
V_{t}^{s}=U\left[b I(t<L)+\beta p \frac{w}{1-\beta}+\beta(1-p) V_{t+1}\right]
$$

where $I(t<L)$ is an indicator function equal to one if $\mathrm{t}<\mathrm{L}$ and zero otherwise.

Disability applications are allowed with probability q, but only after J months of review; I assume that $\mathrm{J}$ is known to the applicants throughout. The model assumes that disability applications have utility cost a. The model also assumes that applicants stop searching after they decide to apply, so they cannot earn unemployment benefits during their wait between application and determination, nor will they receive job offers. Finally, the model assumes that

\footnotetext{
${ }^{7}$ This model is in some ways a simplification of the model in Lindner (2011), ignoring search effort and the possibility of receiving UI benefits during the wait for disability application and adding the assumption that wait time $\mathrm{J}$ is known.
} 
allowed disability determinations are never reviewed, so successful applicants receive disability benefits d permanently. The utility from disability application is:

$$
V_{t}^{d}=U\left[\beta^{J} q \frac{d}{1-\beta}+\beta^{J}(1-q) V_{t+1}\right]-a
$$

In the simplest model, $\mathrm{p}$ and $\mathrm{q}$ are time-invariant; that is, the job finding rate and the success rate of disability application do not depend on the amount of time the individual has been unemployed. In that model, some individuals would apply for disability benefits immediately after job loss, as $V_{0}^{d}>V_{0}^{s}$. Others would never apply for disability, as $V_{t}^{s}>V_{t}^{d}$ even when unemployment benefits are not available $(\mathrm{t} \geq \mathrm{L})$.

As all parameters are time-invariant other than $b I(t<L)$, the only marginal applicants are those whose decision depends on the presence or absence of unemployment benefits. Some individuals will opt to search when unemployment benefits are available $(\mathrm{t}<\mathrm{L})$, but prefer application after UI exhaustion ( $\mathrm{t} \geq \mathrm{L})$, so $V_{t<L}^{s}>V_{t}^{d}>V_{t \geq L}^{S}$. In this simple model of timeinvariant probabilities, individuals only will apply for disability benefits in the first period and at $\mathrm{L}$, as all parameters are otherwise equal within the two time periods ( $\mathrm{t}<\mathrm{L}$ and $\unrhd \mathrm{L}$ ). When UI benefits are extended, so that L is increased to L', the applicants in the initial period (with $V_{0}^{d}>V_{0}^{s}$ ) and those who never apply (with $V_{t}^{s}>V_{t}^{d}$ ) are unaffected, but the marginal applicants will delay application until exactly L’.

A more interesting model is one that allows for $\mathrm{p}$ and $\mathrm{q}$ to vary over time. ${ }^{8}$ The assumption is that $\mathrm{p}^{\prime}(\mathrm{t})<0$, as the longer one is unemployed, the more difficult it is to find a job, and that $q^{\prime}(t)>0$, as the longer one is unemployed, the easier it is to convince the Disability Determination Service that one is unable to work. ${ }^{9}$ In this model, the passage of an additional month reduces $V_{t}^{s}$ and increases $V_{t}^{d}$. Like the time-invariant model, there will be concentrations of applications at both month 0 and month L, but unlike the simpler model, individuals will apply for disability in other months as well. Furthermore, when benefits are extended and $\mathrm{L}$ is

\footnotetext{
${ }^{8}$ The qualitative result is similar if only one of the probabilities varies with time.

${ }^{9}$ Though the literature (e.g., Ruhm 2000) often finds a positive effect of recessions on health, others find that individual job loss results in increased incidence of disability (Gallo, Brand et al. 2009). The first derivative of q with respect to time may also be positive if the negative effect of job loss on health gets worse as the jobless spell continues.
} 
increased to L', individuals who have not yet applied will delay their applications; the local maximum at L moves to L', but a few others will apply in between.

\section{Data}

The Survey of Income and Program Participation (SIPP) is a nationally-representative longitudinal survey of households conducted by the U.S. Census Bureau. Every four months over a two- to four-year period, respondents are asked a battery of questions on their labor market participation, sources of income, employment relationships, demographics and family structure, health insurance status, wealth, and public program participation during each month between interviews. New panels began annually between 1990 and 1993, plus 1996, 2001, 2004, and 2008.

The SIPP Gold Standard File (GSF) matches these panels to disability application data originally from the SSA's 831 File and earnings data originally from both the SSA's Summary Earnings Record (SER) and the IRS’ Detailed Earnings Record (DER). Approximately 88 percent of SIPP respondents over age 15 provided valid Social Security numbers and were successfully matched (Abowd, Stinson, and Benedetto 2006).

The sample for the individual-level regressions includes workers ages 25 to 64 who are observed losing a job during their time in the SIPP panel. An individual has lost a job in month $\mathrm{t}$ if he worked all weeks in month $\mathrm{t}-1$, less than the full number of weeks in month $\mathrm{t}$, and no weeks in month $\mathrm{t}+1$. $^{10}$ The sample excludes individuals with missing work status information at any point, as well as anyone whose state of residence is missing or unidentifiable. ${ }^{11}$ The sample also excludes individuals who have insufficient earnings to receive UI, and those who are ineligible for SSDI. The resulting sample yields approximately 29,000 working-age adults who lost at least one job during their SIPP sampling window from 1990 to 2006. Table 1 details the process of refining the sample from the full SIPP. Table A1 provides summary statistics.

The 831 File includes the date of application, the filing type (SSDI, SSI, or concurrent), and the result of the initial determination for up to four disability applications for each individual

\footnotetext{
${ }^{10}$ Individuals may have more than one jobless spell. The individual's spell is right-censored if he finds a new job, but a subsequent job loss would put him back in the sample a second time. Most individuals have only one spell during the SIPP - the sample includes 33,385 spells for 28,728 unique persons.

${ }^{11}$ Prior to the 2004 panel, several states were combined to prevent identification. In the 1990 through 1993 panels, the following states were grouped together: Maine and Vermont; Iowa, North Dakota, and South Dakota; and Alaska, Idaho, Montana, and Wyoming. In the 1996 and 2001 panels, Vermont was grouped with Maine, and Wyoming was grouped with North Dakota and South Dakota.
} 
through the end of calendar year 2010. ${ }^{12}$ The sample excludes individuals who have ever applied successfully for SSDI prior to the job loss and those who apply in the same month as the job loss. The sample also excludes disability applications more than 48 months after the job loss, as they likely have little to do with health conditions at the time of separation; for non-applicants, the sample censors monthly observations at 48 months as well. ${ }^{13}$

SSDI eligibility and the level of monthly benefits (the primary insurance amount, or PIA) are calculated using the individual's earnings history from the SER. The explanatory variables also include the individual's earnings previous to a job loss and his spouse's earnings in the year of the job loss from the DER; unlike the SER, the DER includes uncapped and non-FICA earnings. The benefits levels and the earnings variables are adjusted for inflation using the Consumer Price Index from the U.S. Bureau of Labor Statistics.

Each state's unemployment insurance parameters are collected from two reports produced annually by the Employment and Training Administration in the U.S. Department of Labor: the "Significant Provisions of State UI Laws" and the "Comparison of State Unemployment Insurance Laws.” ${ }^{14}$ These reports include the formulas for the weekly benefit amount and the duration of unemployment. Because the UI benefit depends on prior quarterly earnings, earnings are imputed for each of the last six quarters by distributing one's annual earnings from the administrative data between the calendar quarters according to the percent of one's total income earned that quarter, or evenly (annual earnings divided by four) for individuals who have not been in the SIPP for a full 18 months prior to the job loss. Though all but a few states have a maximum UI duration of 26 weeks, individual workers may have shorter durations if their earnings were concentrated in one or two quarters. ${ }^{15}$ The Comparison of State Unemployment Laws report also includes information on the unemployment rate thresholds each

\footnotetext{
${ }^{12}$ An application is considered concurrent if the individual has SSDI and SSI applications in the same calendar month.

${ }^{13}$ The longest SIPP panels (1996 and 2004) are 48 months long. Because re-employment is only observed in the SIPP, the empirical probability of finding a job is zero after the end of the individual's SIPP panel.

${ }^{14}$ Both reports are available on the DOL website (http://www.ows.doleta.gov/unemploy/statelaws.asp). The author would like to thank Daniel Hays, Patricia Martens, and Julie Balster from the ETA for their assistance in obtaining pre-2002 editions of the Comparison report.

${ }^{15}$ The Gold Standard File does not include an indicator for whether the individual reports receiving unemployment benefits, so the model in this paper implicitly assumes that take-up is random with respect to the other covariates. Lindner (2011) finds that many seemingly-eligible individuals do not report receiving UI benefits, and differential take-up affects the estimates of the effect of UI benefit generosity on disability application.
} 
state uses in the federal-state Extended Benefits program, as well as the dates of the three emergency UI extensions passed by the U.S. Congress since $1990 .^{16}$

The state unemployment rate is from the Local Area Unemployment Statistics of the U.S. Bureau of Labor Statistics. The insured unemployment rate, the number of individuals receiving UI benefits after the first week (“continuing claims”) divided by the number of workers eligible for or already receiving UI, is from the U.S. Department of Labor's Unemployment Insurance Weekly Claims data.

Monthly state-level disability activity is available from the SSA State Agency Monthly Workload Data from October 2000 to December 2011. A state's monthly application rate is the number of initial receipts divided by the estimated age 18 to 64 population for that state in the given month (excluding current beneficiaries), multiplied by 12 to annualize the rate. ${ }^{17}$ The initial allowance rate is the number of allowances divided by the number of determinations in that state for that month.

\section{Empirical Models}

Individual-level analysis. This study investigates whether jobless workers time their disability application to coincide with the exhaustion of their UI benefits. UI extensions provide additional variation in UI benefit duration, but are interesting in their own right; the study therefore investigates whether UI extensions induce jobless workers to delay disability claims and instead find employment, and whether the composition of applicants changes when UI benefits are extended.

The regression analysis allows for jobless individuals to end their spell through either disability application or re-employment; essentially, these outcomes are competing hazards in

\footnotetext{
${ }^{16}$ Information on the 1991-1994 Emergency Unemployment Compensation is collected from Corson, Needels, and Nicholson (1999), Table A.2.

${ }^{17}$ The estimated age 18 to 64 population for 2000 to 2009 is from the U.S. Census Bureau's Population Estimates Program. To get the 2010 and 2011 estimated working-age state populations, which are not yet available from the Census, the state's 2009 population is regressed on the population in each year from 2000-2008, then used the results to predict 2010 using 2001-2009 and 2011 using 2002-2010. The number of current SSDI beneficiaries is also only available from the Annual Statistical Supplement through 2009; the imputed number of beneficiaries in a state in 2010 and 2011 is the number of beneficiaries in the previous year plus the number of (pro-rated) allowances for that year divided by the mean ratio of allowances to the year-to-year change in recipients for all other years. The state population net of current beneficiaries in a given month is smoothed within a year assuming a constant linear growth rate from month to month.
} 
that applicants could decide to either apply to SSDI or find a job, but only the outcome that occurs first is observed. ${ }^{18}$ To account for these competing hazards, the individual's decision in month $t$ is modeled as a multinomial logit regression, with three potential outcomes, $j$ : applying for SSDI, finding a job, or continuing the jobless spell. ${ }^{19}$ The probability of the individual $i$ choosing outcome $j$ in month $t$ is:

$$
p_{i j t}=\frac{e^{Y_{i j t}}}{\sum_{k=1}^{3} e^{Y_{i k t}}}, \quad j=1, \ldots, 3
$$

where the index function $Y_{i j t}$ is defined as:

$$
\begin{aligned}
Y_{i j t}=\beta_{0 j}+ & \beta_{1 j} \text { NormalUI }_{i t}+\beta_{2 j} \text { NormExpNext }_{i t} \\
& +\beta_{1 j} \text { NormExpNow }_{i t}+\beta_{1 j} \text { NormExpLast }_{i t} \\
& +\beta_{1 j} \text { OnExt }_{i t}+\beta_{1 j} \text { ExtExpNext }_{i t} \\
& +\beta_{1 j} \text { ExtExpNow }_{i t}+\beta_{1 j} \text { ExtExpLast }_{i t} \\
& +\beta_{1 j} \text { InitExp }_{i t}+\beta_{1 j} \text { NewExtBefore }_{i t} \\
& +\beta_{1 j} \text { NewExtAfter }_{i t}+\lambda_{1} U_{s t}+\lambda_{2} U_{s t_{0}}+X_{i s t} \zeta \\
& +v_{i s t}
\end{aligned}
$$

To identify the model, the coefficient vector $\beta$ is constrained to be zero for the baseline outcome, continuing the spell.

The first eight terms in $Y$ are mutually exclusive indicators that capture the effect of UI eligibility, approaching exhaustion, and extension on the application or job-finding decision; the omitted condition is no longer being eligible for UI (excluding the month immediately after exhaustion). The values of these eight indicators, plus the three that follow, depend on whether UI benefits are ever extended during the jobless spell. For defining these variables, the sample can be split into three groups: those whose benefits are never extended, those whose benefits are

\footnotetext{
${ }^{18}$ The estimates of the hazard to SSDI application without regard to the competing hazard of re-employment, assuming either a Weibull or gamma-distributed parametric form or using a more flexible spline of time remaining until UI exhaustion, are qualitatively similar.

${ }^{19}$ All other outcomes, including applying to SSI, losing eligibility for SSDI, dropping out of the SIPP mid-panel, or reaching the maximum of 48 months after job loss, are considered censored. The outcome in the last month for censored observations is the baseline outcome of continued search.
} 
extended before their original UI eligibility is exhausted, and those whose benefits are extended only after a delay.

For all three groups, the first term, NormalUI $I_{i t}$ equals one if jobless individual $i$ is receiving the first few months of the UI duration for which he or she was eligible at the beginning of his or her jobless spell, up to one month before exhaustion. Compared to months when UI is about to expire, both SSDI applications and job-finding should be less likely in the first few months of UI eligibility. Applications and re-employment may be more likely in these months than in months without any UI benefits because of negative duration dependence; that is, those who are many months after job loss are not likely to reach either of these outcomes, because if either option was attractive, they would have done it already.

For the group whose benefits have never been extended, only the next three terms will ever equal one, while the subsequent seven will all equal zero. NormExpNext, NormExpNow, and NormExpLast capture the effect of imminent, current, or having just exhausted UI benefits, respectively. This specification allows for flexibility in the timing of one's reaction to exhausted benefits; some UI recipients may act in anticipation of exhaustion the next month, while others may wait until the first month with no benefits.

For those whose benefits are extended before their initial eligibility is exhausted, the analogous variables are ExtExpNext, ExtExpNow, and ExtExpLast. In addition, OnExt is equal to one when individual $i$ receives UI benefits only because of an ongoing extension, and exhaustion is more than a month away (so as not to overlap with ExtExpNext). Both outcomes should be less likely during months of extended benefits, and grow increasingly likely with the approach of the new UI exhaustion.

For the extended group, two other variables also are relevant. InitExp is equal to one if the individual was scheduled to exhaust his or her UI benefits in the current month based on his or her UI eligibility at the time of job loss. ${ }^{20}$ This variable captures two effects, both of which are expected to encourage application. First, the individual may plan at the outset to apply for

\footnotetext{
${ }^{20}$ Unlike the previous eight indicator variables, InitExp is not a mutually exclusive category. In most cases, though, it will be. Among those whose benefits are never extended, InitExp will always equal zero, because NormExpNow already captures the effect of UI expiring in the current month. If the UI extension is at least two months, when InitExp is equal to one, OnExtequals zero, because UI benefits are still being received under the normal duration. For extensions of less than two months, however, InitExp and ExtExpNext may both equal one; the former captures the effect of the original duration expiring, while the latter captures the effect of imminent UI exhaustion.
} 
disability at the conclusion of his or her UI benefit eligibility, and those plans aren't easily adjusted. $^{21}$ Second, the individual may be unaware or indifferent toward increases in his or her UI duration.

The other pertinent indicator for those whose benefits are extended during their normal duration is NewExtBefore, equal to one if the UI exhaustion point is further away than it was the previous month, where "before" refers to the fact that the UI extension is announced before this individual's benefits are exhausted. An announcement of a new extension has ambiguous effects on applications and job loss; though additional weeks increase the present value of benefits, making either decision less likely at the present time, the announcement itself may be a signal of poor employment prospects, which encourages application or more fervent job searches.

The final group of jobless individuals is those whose benefits are extended during their jobless spell, but only after lapsing at some point. Federal UI extensions usually allow those whose benefits have recently expired to come back on the UI rolls, so some UI recipients have gaps in their UI benefit history. Unlike the other two groups, therefore, all of the indicators for UI receipt, exhaustion, and extension have the potential to be turned on at some point during their spell, with the exception of NewExtBefore. Instead, the relevant variable for the announcement of a new extension is NewExtAfter, where "after" refers to the fact that the new extension occurred after benefits had expired. Separating these two variables allows for differential effects for extensions that occur before they are truly needed versus those that come only retroactively; whereas individuals who know they have additional months of benefits coming may plan accordingly, those whose benefits have expired may begin to make plans to apply for SSDI or find a job before they find out about additional months of UI. $U_{s t}$ and $U_{s t_{0}}$ control for the state unemployment rate currently and at the time of job loss, respectively. Both should have a negative effect on disability application. The effect on job finding is ambiguous; in months of high unemployment, the job offer rate is likely lower, but search effort

\footnotetext{
${ }^{21}$ Meyer (1990) and Katz and Meyer (1990) find that many workers are subject to recall from temporary layoffs, which are often exactly as long as the worker is eligible for unemployment benefits. Disability application is not part of those studies, but workers who are on temporary layoff but not recalled may opt to apply to SSDI in that month, the equivalent of workers who do not have the same recall expectation applying for SSDI in the first month of the jobless spell, a common occurrence. This is likely a small consideration, as temporary layoffs are much less common in recent years than they were in Katz and Meyer’s data (Groshen and Potter 2003).
} 
could be higher, as the unemployed feel the need to compete with a larger number of job seekers, or lower, if the unemployed are discouraged by bleak prospects.

$X_{i s t}$ is a vector of individual characteristics that may influence the decision to apply for disability or find a job. These include the log of real potential UI benefits, calculated from state parameters using imputed quarterly earnings, and the log of real potential SSDI benefits, calculated using the PIA formula. $X_{i s t}$ also includes the log of the individual's real annual earnings in the year prior to the job loss, the log of his or her spouse's real earnings (if married) in the current year, and an indicator for whether the individual is lacking health insurance in the current month. Importantly, $X_{\text {ist }}$ includes an indicator of whether the individual reports either a work-limiting condition or receipt of sick pay, workers' compensation, or veterans' benefits during his or her time in the SIPP; interestingly, many applicants do not have a value of one for this variable, so regression results are reported separately for those who do and do not satisfy one of these conditions. Finally, $X_{i s t}$ includes age at the time of separation and its square, gender, race, education, marital status, number of children, an indicator for foreign born, and the quintile of total wealth among the sample.

In addition to separate estimations of those with and without self-reported work limitations, broadly defined, the model is estimated separately by age (those under 50 at the time of separation versus those 50 and over) and education (those with less than a high school diploma versus those who at least completed high school). Older workers may be more likely to apply for disability benefits, because of a higher probability of a successful application due to declining health and less strict disability criteria ${ }^{22}$ or larger potential benefits due to a longer work history, but less likely to become re-employed, because of the desirability and feasibility of early retirement and the loss of firm- or occupation-specific capital. Lower-skill workers also may be more likely to apply for disability - weak employment prospects may be less desirable than even the uncertain disability application process, while the disability criterion that determines whether the applicant can find suitable work is more easily satisfied when many potential jobs feature physical labor - and less likely to find re-employment than comparable jobless individuals with more education.

\footnotetext{
${ }^{22}$ Chen and van der Klaauw (2008) report on the use of a vocational grid in the determination process that is based on age, educational attainment, and the strenuousness of work. They show that there are discontinuities created by this grid by age, such that an individual older than a certain age (either 45, 50, or 55 depending on the applicant's education) may have their application allowed, while the same application by someone just younger than that age will be denied.
} 
Potential applicants can only guess at the probability of successful application, as the determination depends on numerous factors, some predictable - the severity of the disability as perceived by oneself and one's health care professional, or the relative strictness of the applicant's state SSA office - and others unpredictable - for one, the relative strictness of the examiner within the SSA office (Maestas, Mullen, and Strand 2011). To the extent that eventual success can proxy for the potential applicant's ex-ante perception of his or her own probability of success, allowed and denied applicants may have different responses to UI eligibility, exhaustion, and extension; the macroeconomy; benefit generosity; and other factors. To test whether ultimately allowed and denied applicants are significantly different, an additional multinomial logit regression is estimated, now with three outcomes: successful SSDI application, unsuccessful SSDI application, and finding re-employment.

State-level analysis. This study also uses state-level monthly data to determine whether the aggregate of many individual decisions about whether and when to apply to disability has a substantial impact on application activity.

The advantage to using state-level analysis is that the prediction for the effect of new UI extensions on the composition of applicants, in particular, is somewhat clearer than with the individual data. At a given unemployment rate, a state that extends benefits should see fewer disability applications than a state whose UI recipients receive only their normal duration. Those few applicants who still file when UI benefits are extended are likely to be in worse health and, therefore, have a higher probability of having their application approved. At the state level, then, UI extensions should be associated with a lower application rate and a higher allowance rate, relative to similar states (or that same state at a different time) without extensions. ${ }^{23}$

The challenge to state-level analysis, though, is that it requires more careful consideration of when the effect of UI extensions on the application and allowance rates should be observed. First, state SSA offices report their number of allowances based on the month of determination, not the month of application. According to a report from the SSA Office of the Inspector General (2008), the disability determination process averages 131 days from the time of application to the initial determination. Unlike the individual analysis, where applications can be

\footnotetext{
${ }^{23}$ An additional advantage of the state-level analysis is that the data is more up-to-date and therefore includes the current recession and recovery, unlike the individual-level data. The 2007-2011 period is especially interesting given the length of the UI extensions and the unprecedented growth in disability applications.
} 
split by their eventual success or failure, the state-level analysis makes the assumption that all determinations are made on four-month-old applications. ${ }^{24}$

Second, a new UI extension should have an effect on application and allowance rates for more than just its first month. Jobless workers given a 13-week extension will likely delay their disability application for most, if not all, of those 13 weeks, so the application rate should remain at the new lower level for at least that long. After 13 weeks, those who would have exhausted their benefits absent the extension will finally come off the UI rolls, and the application rate will start to slowly increase. As the weeks go on, more and more UI recipients will exhaust their benefits, and the application rate will likely be restored to near its normal level, even before the extension actually expires. Finally, when the UI extension ends, a few more workers will retain extended benefits for an additional 13 weeks, so the disability application rate should be slightly below normal until 13 weeks after the extension expires. At each stage (and with that fourmonth lag), the healthiest potential disability applicants are most likely to delay applications, so allowance rates should move inversely with the predicted change in application rates. Unlike the individual analysis, which controls for the remaining duration of UI benefits for that recipient directly, the state-level analysis has to account for UI recipients exhausting their benefits on a rolling basis.

The state-level regression model, estimated by ordinary least squares, is:

$$
\begin{aligned}
\text { App }_{s t}=\alpha_{0}+ & \beta_{0} \text { Before }_{s t}+\beta_{1} \text { First }_{s t}+\beta_{2} \text { Ongoing }_{s t} \\
& +\beta_{1} \text { PhaseOut }_{s t}+\theta_{1} U_{s t}+\theta_{2} U_{s, t-6}+\pi_{1} t \\
& +\pi_{2} t^{2}+m_{t}+\xi_{s}+v_{s t} \\
\text { Allow }_{s t}=\alpha_{0}+ & \beta_{0} \text { Before }_{s, t-4}+\beta_{1} \text { First }_{s, t-4} \\
+ & \beta_{2} \text { Ongoing }_{s, t-4}+\beta_{1} \text { PhaseOut }_{s, t-4} \\
+ & \theta_{1} U_{s, t-4}+\theta_{2} U_{s, t-10}+\pi_{1} t+\pi_{2} t^{2}+m_{t}+\xi_{s} \\
+ & v_{s t}
\end{aligned}
$$

The coefficients of interest are on the four mutually exclusive indicator variables for time


or less before the start of the extension; First ${ }_{s t}$, which equals one if the current month is one of

\footnotetext{
${ }^{24}$ The state-level results are robust to the choice of a four-month lag over three-, five-, or six-month lags.
} 
the first $\mathrm{N}$ months in an N-month extension; Ongoing $_{s t}$, which equals one if the current month is after the first $\mathrm{N}$ months, but the extension is still active; and PhaseOut ${ }_{s t}$, which equals one if the current month is within the first $\mathrm{N}$ months after the extension expires. The discussion above suggests that $\beta_{1}, \beta_{2}$, and $\beta_{3}$ are all negative in (2) and positive in (3), but $\left|\beta_{1}\right|>\left|\beta_{2}\right|>\left|\beta_{3}\right|$, so that only $\beta_{1}$ may be significantly different from the omitted condition of no recent or imminent extension.

Importantly, the regression also controls for two measures of the unemployment rate. The literature (e.g., Autor and Duggan 2006) has found a consistent positive correlation between disability applications and $U_{s t}$, the contemporaneous state unemployment rate. ${ }^{25} U_{s, t-6}$, the unemployment rate lagged six months, accounts for the proportion of the state's population that, except for during UI extensions, is exhausting their unemployment benefits in month $\mathrm{t}^{26} \mathrm{New}$ UI extensions occur in too few calendar years to include year fixed effects; instead, the model includes linear and quadratic time trends $-t$ and $t^{2}$, respectively - to account for the secular upward trend in applications. The calendar month fixed effect, $m_{t}$, accounts for seasonal patterns, and the state fixed effect, $\xi_{s}$, controls for time-invariant differences across states in the inclination to apply for disability. ${ }^{27}$

Cost estimates. The final section of the results estimates the increase in cost per jobless individual from a 13- or 26-week UI extension. When UI is extended, additional UI benefits are

\footnotetext{
${ }^{25}$ Most states that extend UI benefit durations also have rising unemployment rates, as the extension comes about because the national unemployment rate is rising, inducing Congress to pass emergency legislation that sends funds to the states for additional benefits, or because state labor market conditions deteriorate enough to trigger automatic increases in benefit duration. Therefore, it can be difficult to separate the effects of new extensions from the worsening economic conditions that trigger them. One approach used in this study is to interact the extension indicators in (2) and (3) with an indicator for whether the unemployment rate in that state has increased by at least 20 percent over the six months before the extension was implemented. The decrease in application rates at the start of these "endogenous" extensions are similar to more "exogenous" extensions that occur when the state's local unemployment rate has been stable, but benefits are extended because of tightening labor markets elsewhere.

Allowance rates increase substantially more in exogenous extensions, as expected, but the magnitude of this increase is not robust to the definition of exogeneity; these results are available upon request.

${ }^{26}$ The unemployment rate is lagged seven months for the few states that had maximum durations of 28 (Montana starting in 2004) or 30 weeks (Massachusetts throughout the sample period, and Washington until 2004).

${ }^{27}$ Coe, Haverstick, Munnell, and Webb (2011) find that state fixed effects explain a significant portion of cross-state differences in disability application rates. This study's results are similar, though the standard errors are somewhat larger, when the model includes the set of state characteristics used in that study, both in lieu of and in addition to state fixed effects. This study include only the state fixed effects, because most state characteristics are available only annually. These state characteristics also are unavailable for 2010 and 2011; the addition of the latter 17 months are important because those months provide additional observations of states that are phasing out extended UI benefits.
} 
paid out until the new exhaustion point or the recipient finds a job, whichever is earlier. This paper suggests a second important change in costs: if a potential SSDI applicant finds a job during the UI extension, or otherwise opts to not apply or significantly delay applying, SSDI benefits paid out could decrease. In addition, because SSDI recipients are eligible for Medicare 24 months after first receipt, delayed or diverted SSDI applications could reduce Medicare expenditures as well.

The multinomial logit regression yields predicted probabilities of applying to SSDI successfully, $P\left(\right.$ Allow $\left._{i t}\right)$, and unsuccessfully, $P\left(\right.$ Denied $\left._{i t}\right)$, for person $i$ in month $t$, as well as the probability of finding a job, $P\left(J o b_{i t}\right)$. Therefore, the probability of continuing to search is: $P\left(\right.$ Search $\left._{i t}\right)=1-P\left(\right.$ Allow $\left._{i t}\right)-P\left(\right.$ Denied $\left._{i t}\right)-P\left(\right.$ Job $\left._{i t}\right)$.

The model assumes a five-month waiting period for the initial determination of SSDI benefits, both because of the lag while the application is reviewed, and the requirement that no benefits are received until at least five months after the onset of the disability. The model further assumes that SSDI benefit receipt is permanent: those who have approved SSDI applications receive benefits from five months after applying until their FRA. Those whose SSDI application is ultimately allowed receive UI benefits for as long as they are eligible or for five months, whichever is earlier, plus Medicare benefits starting 29 months (five months for the determination plus 24 months for Medicare eligibility) after application. Those whose benefits are ultimately denied also receive UI benefits for as long as they are eligible, except that they continue to receive benefits after the five-month waiting period (if they are still eligible). ${ }^{28}$ Those who are continuing to search receive UI benefits until those benefits are exhausted, while those who find a job stop receiving benefits immediately.

An individual i's cost to the UI system depends on i's estimated probability of still receiving benefits and i's individual-specific real benefits, as calculated based on the state of residence and pre-job loss earnings (or zero if the current month $t$ is after the exhaustion point). In month 0 , the first month after job loss, $i$ receives UI benefits if $i$ is searching or has a pending SSDI application (regardless of its eventual outcome), and receives nothing if $i$ finds a job:

\footnotetext{
${ }^{28}$ Every state requires that UI recipients are actively seeking work and able and available to begin work within a short period of time. Few states, however, require such onerous levels of documentation that applicants to SSDI would not be able to receive UI benefits during the period that their applications are pending. Lindner (2011) similarly models SSDI applicants as eligible for UI benefits while applications are pending.
} 


$$
U I \text { Cost }_{i 0}=U I_{i 0}\left[P\left(\text { Allow }_{i 0}\right)+P\left(\text { Denied }_{i 0}\right)+P\left(\text { Search }_{i 0}\right)\right]
$$

In month $1, i$ is in the sample for the multinomial logit regression only if $i$ did not find a job or apply to SSDI in month 0; otherwise, $i$ is no longer "at risk," in the language of hazard models. Person $i$ receives benefits if $i$ has a pending application or is still searching:

$$
\begin{aligned}
\text { UI Cost }_{i 1}= & \text { UI }_{i 1}\left[P\left(\text { Allow }_{i 0}\right)+P\left(\text { Denied }_{i 0}\right)\right. \\
& +P\left(\text { Search }_{i 0}\right)\left[P\left(\text { Allow }_{i 1}\right)+P\left(\text { Denied }_{i 1}\right)\right. \\
& \left.\left.+P\left(\text { Search }_{i 1}\right)\right]\right]
\end{aligned}
$$

Similarly, in month 2, i's UI cost is:

$$
\begin{aligned}
\text { UI Cost }_{i 2}= & U_{i 2}\left[P\left(\text { Allow }_{i 0}\right)+P\left(\text { Denied }_{i 0}\right)\right. \\
& +P\left(\text { Search }_{i 0}\right)\left[P\left(\text { Allow }_{i 1}\right)+P\left(\text { Denied }_{i 1}\right)\right. \\
& +P\left(\text { Search }_{i 1}\right)\left[P\left(\text { Allow }_{i 2}\right)+P\left(\text { Denied }_{i 2}\right)\right. \\
& \left.\left.\left.+P\left(\text { Search }_{i 2}\right)\right]\right]\right]
\end{aligned}
$$

More generally, $i$ 's UI cost in month $t$ is: ${ }^{29}$

$$
\begin{aligned}
{\text { UI } \text { Cost }_{i t}=} U_{i t} & \left\{\left[\sum _ { \tau = 0 } ^ { t } \left[P\left(\text { Allow }_{i \tau}\right)\right.\right.\right. \\
& \left.\left.+P\left(\text { Denied }_{i \tau}\right)\right] \prod_{s=0}^{\tau-1} P\left(\text { Search }_{i s}\right)\right] \\
& \left.+P\left(\text { Search }_{i t}\right) \prod_{r=0}^{t-1} P\left(\text { Search }_{i r}\right)\right\}
\end{aligned}
$$

The term in the square brackets represents the probability of having applied for SSDI benefits (regardless of determination) any time before month $t$; the product term accounts for the fact that person $i$ could only apply for SSDI if he or she had not previously applied or found a job in any of the previous months. The second term, outside of the square brackets, is the probability of still searching in month $t$, which is conditional on having searched in all previous months.

\footnotetext{
${ }^{29}$ For ease of notation, the probability of search for any month that appears to be out of range (such as $t-29$ when $t<29$ ) is assumed to equal one, and the probability of applying to SSDI successfully or unsuccessfully is zero.
} 
Person i's cost to the SSDI system in month $t$ is similarly derived, with the simplification that only the probability of having applied successfully at least five months before $t$ matters. As in equation (4), i's cost also depends on the individual-specific real PIA calculated from i's earnings history. In addition, $i$ will be eligible for Medicare 29 months after submitting a successful application; the real cost of Medicare benefits is approximated by the average monthly cost of disabled Medicare enrollees in the given year (see Appendix Table A2). The total cost for $i$ if he or she is approved for SSDI benefits is:

$$
\begin{aligned}
\text { SSDI Cost }_{i t}= & \text { PIA }_{i t}\left\{\sum_{\tau=0}^{t-5} P\left(\text { Allow }_{i \tau}\right) \prod_{s=0}^{\tau-1} P\left(\text { Search }_{i s}\right)\right\} \\
& + \text { Medicare }_{t}\left\{\sum_{\tau=0}^{t-29} P\left(\text { Allow }_{i \tau}\right) \prod_{s=0}^{\tau-1} P\left(\text { Search }_{i s}\right)\right\}
\end{aligned}
$$

Finally, i’s long-run cost to the SSDI program includes the time-discounted cost of SSDI and Medicare benefits until $i$ reaches his or her FRA (between 65 and 67 depending on $i$ 's year of birth), which occurs in month $T_{R}$. The model inputs the expected SSDI and Medicare cost in the last period, $t_{L}$, into the formula for a geometric sum between $t_{L}$ and $T_{R}:^{30}$

$$
\text { LRSSI Cost }{ }_{i}=\left(\text { PIA }_{i, t_{L}}+\text { Medicare }_{i, t_{L}}\right) \frac{\left(\phi_{t_{L}}^{\left(\frac{t_{L}}{12}\right)}-\phi_{t_{L}}^{\left(\frac{T_{R}-t_{L}}{12}\right)}\right)}{1-\phi_{t_{L}}}
$$

where $0<\phi_{t_{L}}=1 / 1-\left(\frac{r_{t_{L}}}{100}\right)<1$, the discount factor using the 20-year Treasury bond rate in the year of $t_{L}$ as the discount rate $\left(r_{t_{L}}\right)$.

\section{Results}

\footnotetext{
${ }^{30}$ This calculation assumes a constant real cost of Medicare. In fact, Medicare costs have exceeded the rate of inflation in recent years. This calculation, therefore, represents a lower bound on the long run expected per-person cost of SSDI among those experiencing a job loss.
} 
Individual-level Analysis. Figure 2 and Table 2 both provide evidence that individuals consider their remaining unemployment insurance benefits in the timing of their disability application. Figure 2 plots the survivor function, the proportion of the sample that has not yet applied for either SSDI after each period, separately by whether the individual's benefits were extended during their jobless spell. Many individuals who eventually apply for SSDI benefits do so in the first three months after losing a job; the survivor function is steepest between the first two points for both those who never have benefits extended and those who have a longer-thannormal duration at the outset of their jobless spell but are not further extended. After the first three months, the survivor function falls at a relatively constant rate. The survivor function is quite different for those whose benefits are extended (or extended further, if they are already longer than normal at the time of job loss) during their jobless spell: the survivor function is rather flat for the first months, and gets steeper over time. The increasing steepness in the unconditional survivor function is remarkable in light of the fact that benefits are extended typically in poor economic conditions; as seen in the state results, jobless individuals in slack labor markets should be inclined to apply for disability benefits faster, not slower.

Table 2 measures whether the timing of SSDI application coincides with the timing of UI exhaustion more directly. Each cell in Table 2 is the number of applications in the months before and after UI exhaustion, standardized to reflect that the periods are not of equal length. ${ }^{31}$ The number of disability applications ticks up in the month that UI is exhausted, particularly for individuals whose benefits are extended during their jobless spell, probably reflecting pent-up demand from the months during the extension. This is less the case for individuals whose benefits are never extended, though this table does not take into account survivor bias; that is, because individuals drop out of the analysis after they've applied for disability, each successive period includes fewer potential applicants "at risk," so increases in later periods are that much more meaningful.

Figure 2 and Table 2 only consider one potential exit for the unemployed - SSDI application. Most jobless individuals instead find re-employment. Others, even if they do not find a new job, may never apply for SSDI or SSI if their perceived probability of success is too

\footnotetext{
${ }^{31}$ For example, the average individual in the sample spends 4.9 months in the first period, greater than two months until UI is exhausted, though this varies from three-and-a-half months for people whose UI is never extended, to more than seven months for those whose benefits are extended during the jobless spell. The number of applications in the period is divided by the average number of months in that period (by extension category) to get the entries in Table 2.
} 
low to justify the application costs. Figure 3 splits the sample by those who find a job, apply for SSDI or SSI, or are censored, either by losing eligibility, missing waves of the SIPP mid-panel, or by reaching the maximum of 48 months after job loss. Among those whose UI benefits are of normal duration throughout their spell, 5.2 percent apply for SSDI and 62.4 percent find a new job. As expected, the SSDI application rate is lower (2.7 percent) for those whose benefits are extended. Perhaps more surprisingly, the proportion who exit the sample by finding a new job is also lower, 46.5 percent, so disability applicants who delay the decision to apply to SSDI or SSI do not appear to find jobs instead. As noted above, this may be due to the fact that individuals whose benefits are extended tend to face more difficult labor markets; indeed, the proportion of those with extended benefits who reach 48 months without either finding a job or applying for disability is nearly double the proportion of those with normal UI duration.

These concerns about survivor bias and confounding macroeconomic factors motivate the multinomial logit model, presented in Table 3. The point estimates in the first two columns represent the marginal effects of each variable on the probability of applying to SSDI or finding a job, respectively, relative to the baseline outcome of continuing the jobless spell, for the full sample of jobless individuals. ${ }^{32}$ All specifications include fixed effects for the month since separation, to account for duration dependence, and demographic controls. ${ }^{33}$

The top portion of Table 3 reports the coefficients and marginal effects for the indicators of UI eligibility, extension, and exhaustion. Approximately 0.25 percent of the sample applies to SSDI in any given month, while 3 percent find a new job in the average month (top line). The first estimate indicates that individuals who are receiving UI during its normal duration are 29 percent more likely to apply for SSDI benefits, and 10 percent less likely to find a job, than similar individuals who exhausted UI at least one month before (the omitted condition); only the latter difference is statistically significant. ${ }^{34}$

The next three estimates focus on individuals whose UI benefits have not been extended since the start of the jobless spell, and whose UI eligibility is coming to an end. These individuals are 44 percent more likely to apply for SSDI in the month of exhaustion, and 7

\footnotetext{
${ }^{32}$ The marginal effect is defined as the change in the predicted probability (or hazard) of application or reemployment from making a small change in the variable (for a continuous variable) or the difference between values of 1 and 0 for all observations (for a binary variable). Standard errors for the marginal effects are calculated by the Delta Method.

${ }^{33}$ These estimates are suppressed for space and are available upon request.

${ }^{34}$ In the text, results are presented as the marginal effect divided by the average monthly hazard rate.
} 
percent less likely to find re-employment, both statistically significant differences from UIineligible months.

The next five estimates focus on individuals whose UI benefits have been extended. The most relevant - and statistically significant - result is the second one: individuals are far less likely to apply for SSDI (58 percent) or find a job (26 percent) during months when they are receiving benefits only because of an extension. During the month that UI had been originally scheduled to expire, individuals are slightly more likely to apply for SSDI, but the estimate is not statistically significant. Job finding is 30 percent less likely in that same month than in UIineligible months, a statistically significant difference and one that stands in contrast to Meyer's (1990) finding that recalls from temporary layoffs were important in his data the late 1970s and early 1980s. The results also suggest that SSDI application almost doubles in the final month of the UI extension but the estimate is not statistically significant.

Finally, there appears to be little effect of the announcement of UI extensions, either before they actually are needed or when they are needed immediately, on the hazard to SSDI application. Individuals who learn of a new UI extension while still eligible, however, are 17 percent less likely to find a job in that same month than in other months with the same values for the UI exhaustion indicators. ${ }^{35}$

The other four columns present the results of separate multinomial logit estimations for those without and with self-reported work limitations or the receipt of benefits that could be associated with disability, including veterans' benefits or workers' compensation. The estimates for the indicators along the UI eligibility timeline are largely similar to the full sample. Both groups are significantly less likely to find a job during extensions. Those without work limitations are more likely to apply for SSDI around the time of non-extended UI exhaustion relative to non-UI months, but the result is not statistically significant. Work-limited individuals are a statistically significant 61 percent less likely to apply for SSDI benefits during a UI extension. After an extension, the probability that a work-limited individual applies to SSDI in

\footnotetext{
${ }^{35}$ Because the indicators for new UI extensions are not mutually exclusive with the other UI eligibility indicators, the probability of finding a job could be even lower if, for example, the UI extension adds to a previous extension. In that case, the hazard to job finding is projected to be 43 percent lower -17 percent lower due to the extension announcement, and an additional 26 percent lower due to having extended benefits already - relative to similar individuals who are no longer eligible for UI.
} 
their final month of UI eligibility almost doubles (191 percent), a difference with non-UI months that is statistically significant at the 90 percent level.

The pattern is also roughly similar for jobless individuals above and below age 50 at the time of separation, and between those with or without a high school degree (Appendix Table A3). Both older and younger workers have spikes in the SSDI application hazard at UI exhaustion, but neither is statistically significant. Similarly, both more- and less-educated potential applicants may be more likely to apply in the last month of UI eligibility or immediately after, though the estimate is not statistically significant in either case. As with the full sample and those with and without work limitations, the point estimates for SSDI application during UI extensions are large and negative for all four subgroups, but only significant for older or less-educated workers. Job finding results are of similar magnitude to the results in Table 3 and more likely to be statistically significant than estimates of the SSDI hazard for these groups.

Figures $4 \mathrm{a}$ and $4 \mathrm{~b}$ use the estimates from Tables 3 and A3 to graph the predicted probability of applying to SSDI for each period of UI eligibility, extension, and exhaustion. Figure 4a shows a noticeable spike in the SSDI hazard in the month that normal (non-extended) UI expires, particularly for the three subgroups most likely to apply for SSDI: those with work limitations, those over age 50 at the time of job separation, or those with less than a high school education. The spike is even larger at the end of UI extensions (Figure 4b) for those with work limitations, while for those over 50 or with less than a high school degree, the spike is actually delayed until the month after extended benefits expire. The probability of applying to SSDI falls for all groups during UI extensions.

Coe et al. (2011) find that SSDI-only applications are much more responsive to UI duration than applications for both SSDI and SSI concurrently, suggesting that the above results underestimate the effect of UI eligibility and extension on SSDI alone. Appendix Table A4 presents the results of an alternative specification, treating SSDI-only and concurrent application. The decrease in the probability of any disability application during a UI extension is concentrated among SSDI-only applications, as the estimate for concurrent applications is small and not statistically different from zero, which echoes the results in Coe et al. The increased probability of applying to disability after UI exhaustion, however, increases for both SSDI-only and concurrent applications, though the samples are too small to reject the null hypothesis of no effect. 
The individual analysis can also indicate whether UI extensions alter the composition of SSDI applicants, if ultimately successful applicants are more or less responsive to UI eligibility than ultimately unsuccessful applicants. Table 4 reports full-sample results of a multinomial logit regression with three possible outcomes (besides the baseline of continuing the jobless spell): applying for SSDI and having that application allowed at the initial determination, applying for SSDI and being denied at the initial determination, and finding a job.

The conceptual framework suggests that, if applicants' ultimate success rate is relatively predictable, denied applications should decrease by more than allowed applications when UI is extended and should increase by more around the time that UI benefits are exhausted. Instead few of the estimates are statistically significant, either in their difference from non-UI months or from each other. The decline in the SSDI hazard is of about equal magnitude for allowed and denied applications during UI extensions, and both are statistically significant compared to nonUI months. After normal UI durations, the estimates suggest that the story is reverse - the hazard to an allowed application increases in both the month of and the month after UI exhaustion, with no change in denied applications.

Still, some estimates in Table 4 provide suggestive evidence that more marginal applicants are induced to apply for SSDI by incentives in the timeline of UI benefits. First, the probability of submitting a denied application, after falling significantly just before UI exhaustion, more than doubles in the last month of a UI extension, but the marginal effect is not statistically significant. One month later, the probability of submitting a successful SSDI application is significantly lower.

Another piece of evidence in support of the conceptual framework is the estimated effect of health insurance status on successful and unsuccessful applicants. Potential applicants who are uninsured are 21 percent more likely to submit an ultimately denied application to SSDI, a statistical significant difference versus those with health insurance coverage, and 17 percent less likely to apply to SSDI successfully. Both results are consistent with the conceptual framework relatively healthier jobless individuals may apply for SSDI in order to obtain Medicare coverage after the 24-month waiting period, while relatively healthier potential applicants do not have the luxury of waiting so long for affordable care and find alternative resources (though perhaps not their own employment, as the probability of finding a job is lower for the uninsured). 
State-level results. The state-level analysis provides stronger evidence in favor of the hypothesis that healthier individuals delay applications to SSDI when extended UI benefits are available. Table 5 presents the results from OLS regressions of state application and allowance rates on indicators for imminent or recent UI extensions. Months without a recent UI extension and with no extension coming in the next 12 months are the omitted condition. Consistent with the individual-level analysis, applications fall by 2.6 percentage points (the second coefficient from the top), or about 2.8 percent of the 0.94 percent mean application rate, in the first $\mathrm{N}$ months of an N-month extension, when all of the recently unemployed in the state are eligible for extended benefits. Application rates then begin to rise, as those who delayed SSDI applications exhaust even their extended UI benefits, and they are highest in the last months of the UI extension, when only those who have been grandfathered in are still eligible for UI. Surprisingly, SSDI applications fall even before the introduction of the UI extension, but this may be due to a delayed reaction to the end of the macroeconomic expansion. As expected, the application rate increases with both the contemporaneous and the lagged state unemployment rate; when the local labor market tightens, SSDI application becomes more attractive, especially to those who have exhausted their UI eligibility.

Matching the hypothesis, the state allowance rate rises in the first few months of a UI extension, while all of the state's recently unemployed are eligible for UI benefits. This increase of just over 1.2 percentage points, or 3.3 percent of the 37.4 percent mean allowance rate, is likely due to healthier potential applicants postponing their decision to file for SSDI benefits until after UI benefits are exhausted, leaving only higher-probability applicants in the pool.

The increase in the allowance rate is also consistent, however, with potentially disabling health conditions, especially mental illness and stress-related conditions, becoming worse with the onset of a recession. Another possibility is that the probability of any individual application being approved may increase during recessions, because there are fewer jobs that the disability applicant could perform. These latter two arguments may explain why the allowance rate remains about 0.7 percentage points higher in later months of the UI extension, though this difference with non-extended months is not statistically significant.

Cost estimates. Table 6 presents the results of a simulation that provides estimates of the expected cost to the UI, SSDI, and Medicare systems of additional weeks of UI benefits, using 
the estimates from Table 4 to calculate the probability of finding a job or applying successfully or unsuccessfully to SSDI. The simulation multiplies the individual's own UI and SSDI benefits by the conditional probability of earning those benefits to get the individual's expected cost in each month, and then sums those expected costs.

The top panel of Table 6 presents the mean, standard deviation, and median over the full sample of the cost for each program for UI durations of different lengths. When all individuals are eligible only for UI for the duration to which they're entitled at the start of their jobless spell (which may be longer than normal, if benefits have previously been extended), the median jobless person in the sample costs the entire system $\$ 2,067$ in expectation. Of that total, $\$ 1,417$ consists of expected UI benefits, and almost exactly $\$ 500$ consists of expected SSDI and Medicare costs, including the long run costs of SSDI and Medicare until the jobless individual reaches FRA. ${ }^{36}$ Mean costs are slightly higher for UI and more than double that of the median for SSDI and Medicare, suggesting that the cost distribution is skewed to the right by individuals expected to have a long duration of disability receipt.

Increasing the duration of UI benefits by 13 weeks for all individuals in the sample, starting from a random point within the first nine months of the jobless spell, results in a new median total cost of $\$ 2,314$, with a median increase of 10.5 percent. The cost of UI benefits increases by 17.8 percent; given that 13 weeks is about 37 percent of the average number of weeks for which an individual is eligible (including extensions), just over 35 weeks, this increase indicates that not everyone delays SSDI application or job finding until only after extended UI benefits are exhausted. As hypothesized, about half (a median decline of 6.9 percentage points) of the UI cost increase is offset by cost savings from lower SSDI and Medicare benefits.

A 26-week extension of UI benefits on top of the duration at the start of each person's jobless spell, similar to extensions in the 1991-93 and 2008-11 recessions, increases costs further, at a slightly increasing rate. The median expected total cost per individual in the sample is $\$ 2,639$, a median increase of 25 percent over the non-extension regime, or about 12 percent more than a 13-week extension. The cost of extra UI benefits more than doubles, while the savings from reduced SSDI and Medicare costs grows, but at a decreasing rate.

\footnotetext{
${ }^{36}$ The summary statistics in Table 6 are calculated separately for each program and for the total. As a result, the sum of the means (or medians) of the costs of the programs will not exactly equal the mean (or median) total cost. The percent changes reported in the last three columns are also the summary statistics for each individual's percent change in cost, so these figures will not match the percent change one could calculate from the first three columns.
} 
The lower panel reports the summary statistics for expected costs for the same simulation but calculated over just the work-limited individuals in the sample. This group is most likely to both apply for disability benefits and use the full duration of UI, because work-limited individuals are less likely to find re-employment in any period, so expected costs are uniformly higher. The median expected total cost increases from \$3,350 to \$3,540 with a 13 -week extension, and increases further to about $\$ 3,820$ with a 26 -week extension. Compared to the full sample, the median cost increase is smaller, only 4.7 percent for the short extension, and an additional 7.1 percent for the longer extension. With each potential extension, the magnitudes of the cost increase for the UI program and the cost decrease for SSDI and Medicare are slightly higher the cost decrease for the full sample, but UI costs increase by more for the work-limited sample, so SSDI and Medicare offset less of the increase.

\section{Conclusion}

As of April 27, 2012, almost four years after unemployment insurance durations were extended by between 20 and 33 weeks nationwide, the Emergency Unemployment Compensation Act of 2008 is still in effect. Residents of every state are still eligible for 34 weeks of UI benefits on top of their normal, state-funded UI duration; all but 11 states are eligible for an additional 13 weeks; and the unemployed in 18 states (including Washington D.C.) are still eligible for Tier Four benefits totaling as many as 99 weeks. Though many workers who lost their jobs at the onset of the Great Recession have long since exhausted even these lengthy UI durations, research should inform policymakers about whether other already overburdened public programs, including SSDI, need to fear further strain from yet more displaced and desperate working-age adults.

The results of this study suggest that jobless individuals delay applying to SSDI until after they have exhausted their unemployment benefits. UI extensions push out these exhaustion dates; this study finds evidence at both the individual- and state-levels that the unemployed respond in-kind. Jobless individuals are significantly less likely to apply for SSDI while they benefit from extra months of UI. This study also observes that in states where UI has been extended, allowance rates in subsequent months rise, indicating that only the unhealthiest potential applicants continue to seek SSDI benefits. 
Public disability insurance programs are structured as long-term programs - applicants are required to demonstrate that their disabling conditions limit their ability to work permanently or over the long term, and few beneficiaries leave the program except through reaching the FRA or death. Demand for these programs, then, should not respond to short-run business cycle fluctuations. One interpretation of this paper's findings is that disability insurance is being used, at least in part, to supplement unemployment insurance, a departure from its intended purpose made all the more expensive because any less-than-deserving recipient is on the rolls more or less permanently.

On the other hand, it is less clear whether the individuals who apply for disability benefits as soon as they exhaust their UI benefits would have applied sooner if UI had not been available. Unemployment benefits are comparable to SSDI benefits, averaging, for jobless individuals in the SIPP, \$233 per week for UI versus \$963 per month for SSDI. The upside to unemployment benefits is that the income is received with almost 100 percent certainty, whereas disability applicants are far more likely to be rejected, and even successful applicants must wait for the decision. In addition, SSDI requires a five-month waiting period between the onset of disability and the first payment of benefits, so UI supports recently employed disability applicants in the interim. Both programs require non-trivial effort, but the Social Security interviews and acquiring medical clearance from doctors probably outweigh calling in to UI's automated phone system once a week to confirm that the recipient is still searching for a job.

Considering all of these factors, perhaps the more interesting finding is that the individuals who are induced to apply due to UI expiration do not apply even sooner. This is especially true for those who delay application during the UI extension. While they have a stronger case for being unable to work after six months of joblessness compared to immediately after job loss, the marginal increase in the allowance rate from an additional three to six months is likely small. These arguments suggest that the perceived costs of applying to SSDI including effort and transaction costs, psychic costs, and lost resources during the wait for the determination - are quite high. This finding also suggests that work-limited individuals cling to their hopes of finding new work, as suggested by accounts in the popular press (Rich 2011), and only the loss of their last, best income source induces them to seek respite in the SSDI system.

The conceptual framework outlined above suggests that the individuals most likely to delay application to SSDI are those who are healthier, and thus less likely to be approved; 
indeed, state allowance rates increase during the first few months of a new UI extension. Because healthier individuals are also more likely to find re-employment, the logical conclusion is that UI extensions should lead to fewer applications to SSDI, decreasing the expected cost of SSDI benefits and, further down the road, Medicare payments on behalf of SSDI beneficiaries. The simulation results appear to confirm this hypothesis, as savings from reduced SSDI and Medicare costs over the long run project to offset about half of the increase in UI benefits from a 13-week extension, though the offset increases less than proportionally for a 26-week extension, which is more in line with legislation during recent recessions.

These results suggest that extended UI benefits decrease the efficiency loss from marginal SSDI recipients leaving the labor force essentially permanently. For as long as potential disability applicants delay their application in favor of unemployment benefits, costs are borne by the UI system, rather than SSDI. Experience-rated taxes on former employers fund normal UI durations, with the incidence of these taxes borne by employees and employers, an insurance system that is likely more efficient than inducing the unemployed to apply for effectively permanent benefits. The federal government pays for all of the cost of benefits that are extended by emergency legislation, and half of the Extended Benefits program, out of general revenue; these actions are important short-run macroeconomic stabilizers and, unlike any similar action taken by individual states, can be financed by countercyclical deficits. Delayed application, therefore, effectively transfers funds from these sources into the SSDI Trust Fund, the same transfer that will occur more explicitly, absent substantial reform, if the Trust Fund is exhausted in 2016 as currently projected (Social Security Trustees Report 2012).

Debates over the merits of UI benefit extensions focus on the program costs, which include both the dollar value of extra benefits distributed to those eligible and the efficiency cost of job search disincentives, and the direct benefits to UI recipients without alternative income sources. This paper suggests that these debates miss an important indirect benefit of UI extensions: increased efficiency due to delayed disability benefits. Moreover, UI extensions provide recipients with more incentive to find a job than they would have while receiving permanent disability benefits, which hopefully defrays even more of the long-run cost. Ignoring these indirect benefits has likely led to fewer, shorter, and more controversial UI extensions than a more complete accounting would suggest. 


\section{References}

Abowd, John M., Martha Stinson, and Gary Benedetto. 2006. "Final Report to the Social Security Administration on the SIPP/SSA/IRS Public Use File Project.” Available at http://www.census.gov/sipp/SSAfinal.pdf

Autor, David H. and Mark G. Duggan. 2003. "The Rise in the Disability Rolls and the Decline in Unemployment.” Quarterly Journal of Economics 118(1): 157-206.

Autor, David H. and Mark G. Duggan. 2006. "The Growth in the Social Security Disability Rolls: A Fiscal Crisis Unfolding.” Journal of Economic Perspectives 20(3): 71-96.

Autor, David H. and Mark G. Duggan. 2010. Supporting Work: A Proposal for Modernizing the U.S. Disability Insurance System. Washington DC: Center for American Progress and the Hamilton Project.

Black, Dan, Kermit Daniel, and Seth Sanders. 2002. “The Impact of Economic Conditions on Participation in Disability Programs: Evidence from the Coal Boom and Bust.” American Economic Review 92(1): 27-50.

Bound, John and Richard Burkhauser. 1999. "Economic Analysis of Transfer Programs Targeted on People with Disabilities.” Handbook of Labor Economics, Vol. 3, edited by Orley Ashenfelter and David Card, pp. 3417-3528. Amsterdam: North-Holland.

Card, David and Philip B. Levine. 2000. "Extended benefits and the duration of UI spells: evidence from the New Jersey extended benefit program.” Journal of Public Economics 78: 107-138.

Chen, Susan and Wilbert van der Klaauw. 2008. "The work disincentive effects of the disability insurance program in the 1990s.” Journal of Econometrics 142: 757-784.

Coe, Norma B., Kelly Haverstick, Alicia H. Munnell, and Anthony Webb. 2011. "What Explains State Variation in SSDI and SSI Application Rates?” Working Paper (forthcoming). Chestnut Hill, MA: Center for Retirement Research at Boston College.

Corson, Walter, Karen Needels, and Walter Nicholson. 1999. “Emergency Unemployment Compensation: The 1990’s Experience.” Working Paper. Washington, DC: U.S. Department of Labor. 
Elsby, Michael W. L., Bart Hobijn, and Aysegul Sahin. 2010. “The Labor Market in the Great Recession.” Brookings Papers on Economic Activity.

Gallo, William T., Jennie E. Brand, Hsun-Mei Teng, Linda Leo-Summers, and Amy L. Byers. 2009. "Differential Impact of Involuntary Job Loss on Physical Disability Among Older Workers: Does Predisposition Matter?” Research on Aging 31: 345-360.

Gritz, R. Mark and Thomas MaCurdy. 1997. "Measuring the Influence of Unemployment Insurance on Unemployment Experiences.” Journal of Business and Economics Statistics 15(2): 130-152.

Groshen, Erica L. and Simon Potter. 2003. "Has Structural Change Contributed to a Jobless Recovery?” New York: Federal Reserve Bank of New York, Current Issues in Economics and Finance 9(8).

Henningsen, Morten. 2008. "Benefit Shifting: The Case of Sickness Insurance for the Unemployed.” Labour Economics 15: 1238-1269.

Jurajda, Stepan and Frederick J. Tannery. 2003. “Unemployment Durations and Extended Unemployment Benefits in Local Labor Markets.” Industrial and Labor Relations Review 56(2): 324-348.

Katz, Lawrence F. and Bruce D. Meyer. 1990. "The Impact of the Potential Duration of Unemployment Benefits on the Duration of Unemployment.” Journal of Public Economics 41: 45-72.

Larsson, Laura. 2006. "Sick of Being Unemployed? Interactions between Unemployment and Sickness Insurance.” Scandinavian Journal of Economics 108(1): 97-113.

Lindner, Stephan. 2011. "How Does Unemployment Insurance Affect the Decision to Apply for Social Security Disability Insurance?” Working Paper (forthcoming). Chestnut Hill, MA: Center for Retirement Research at Boston College.

Maestas, Nicole , Kathleen J. Mullen, and Alexander Strand. 2011. “Does Disability Insurance Receipt Discourage Work? Using Examiner Assignment to Estimate Causal Effects of SSDI Receipt.” Working Paper. Santa Monica, CA: RAND Corporation.

Meyer, Bruce D. 1990. “Unemployment Insurance and Unemployment Spells.” Econometrica 58(4): 757-782. 
Moffitt, Robert. 1985. "Unemployment Insurance and the Distribution of Unemployment Spells.” Journal of Econometrics 28: 85-101.

Moffit, Robert and Walter Nicholson. 1982. "The Effect of Unemployment Insurance on Unemployment: The Case of Federal Supplemental Benefits." The Review of Economics and Statistics 64: 1-11.

Mortensen, Dale T. 1977. "Unemployment Insurance and Job Search Decisions.” Industrial and Labor Relations Review 30: 505-517.

Office of the Inspector General. 2008. "Disability Claims Overall Processing Times." Washington DC: Audit Report A-01-08-18011.

Pellizzari, Michele. 2006. "Unemployment duration and the interactions between unemployment insurance and social assistance.” Labour Economics 13: 773-798.

Rich, Motoko. 2011. “Disabled, but Looking for Work.” New York Times, April 6.

Roed, Knut and Tao Zhang. 2005. "Unemployment Duration and Economic Incentives - A Quasi Random-Assignment Approach.” European Economic Review 49: 1799-1825.

Ruhm, Christopher J. 2000. “Are Recessions Good For Your Health?” Quarterly Journal of Economics 115: 617-650.

Rupp, Kalman and Charles Scott. 1998. "Determinants of Duration on the Disability Rolls and Program Trends.” In Growth in Disability Benefits: Explanations and Policy Implications, edited by Kalman Rupp and David Stapleton, pp. 139-176. Kalamazoo, MI: Upjohn Institute for Employment Research.

Rupp, Kalman and David Stapleton. 1995. "Determinants of the Growth in the Social Security Administration's Disability Programs - An Overview.” Social Security Bulletin 58(4): 43-70.

Stapleton, David C., Kevin A. Coleman, Kimberly A. Dietrich, and Gina A. Livermore. 1998. "Econometric Analyses of DI and SSI application and Award Growth.” In Growth in Disability Benefits: Explanations and Policy Implications, edited by Kalman Rupp and David Stapleton, pp. 31-92. Kalamazoo, MI: Upjohn Institute for Employment Research.

Strand, Alexander. 2002. "Social Security Disability Programs: Assessing the Variation in Allowance Rates.” ORES Working Paper Series No. 98. Washington, DC: Social 
Security Administration, Office of Policy and Office of Research, Evaluation and Statistics.

U.S. Social Security Administration. 2010. Office of Retirement and Disability Policy. Annual Statistical Supplement. Available at http://www.ssa.gov/policy/docs/statcomps/supplement/2010/tempdisability.html.

U.S. Social Security Administration. 2012. The 2012 Annual Report of the Board of Trustees of the Federal Old-Age and Survivors Insurance and Federal Disability Insurance Trust Funds. Available at http://www.ssa.gov/oact/TR/2012/index.html.

Whittaker, Julie M. and Katelin P. Isaacs. 2011. "Extending Unemployment Compensation Benefits During Recessions.” Working Paper. Washington DC: Congressional Research Service. 
Figure 1. Unemployment Insurance Duration

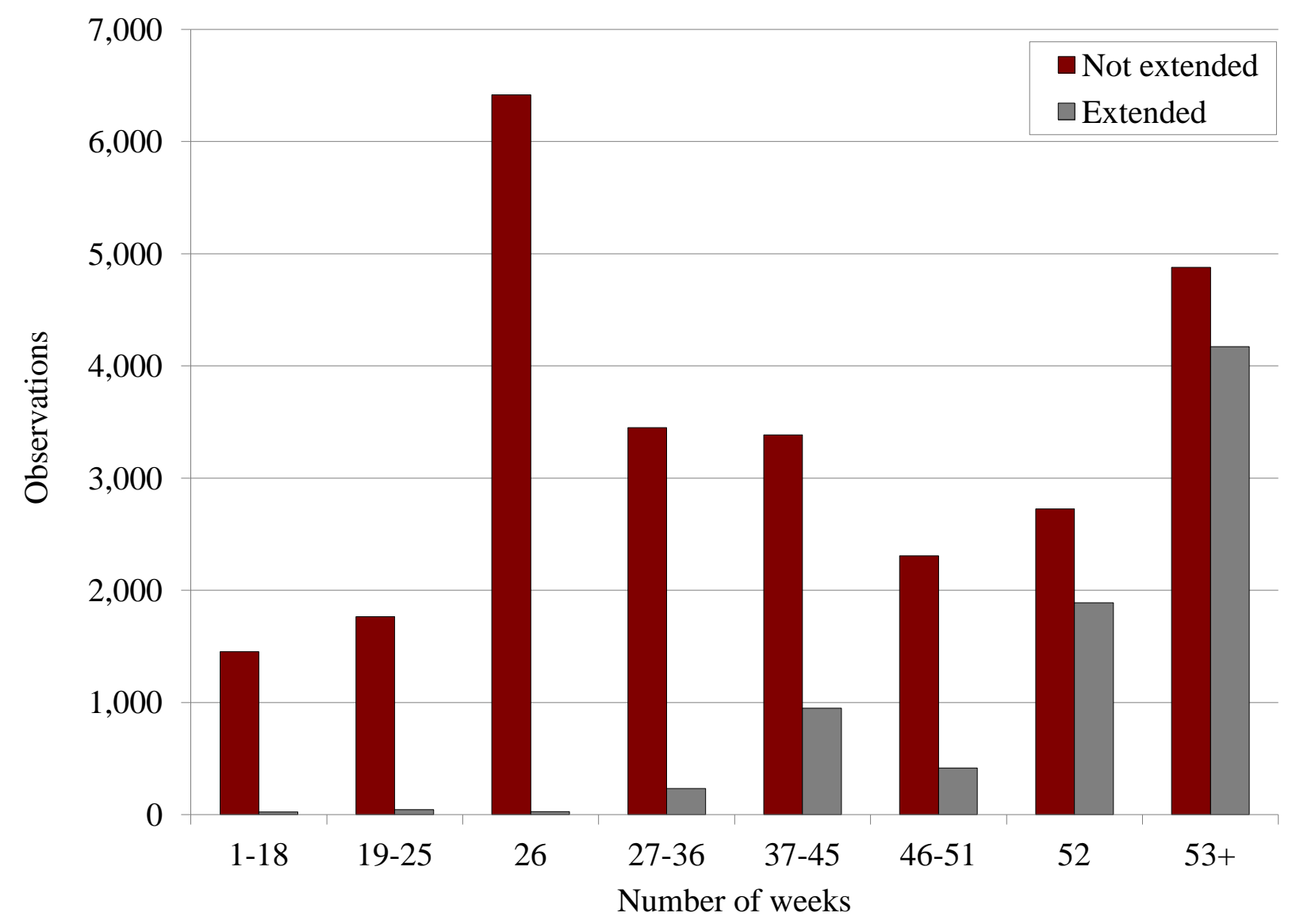

Source: Author's calculations from the Survey of Income and Program Participation Gold Standard File. 
Figure 2. Survivor Functions from Time of Job Loss, by Whether Benefits are Extended



Source: Author's calculations from the Survey of Income and Program Participation Gold Standard File. 
Figure 3. Reason for Exiting Sample, by Extension Type

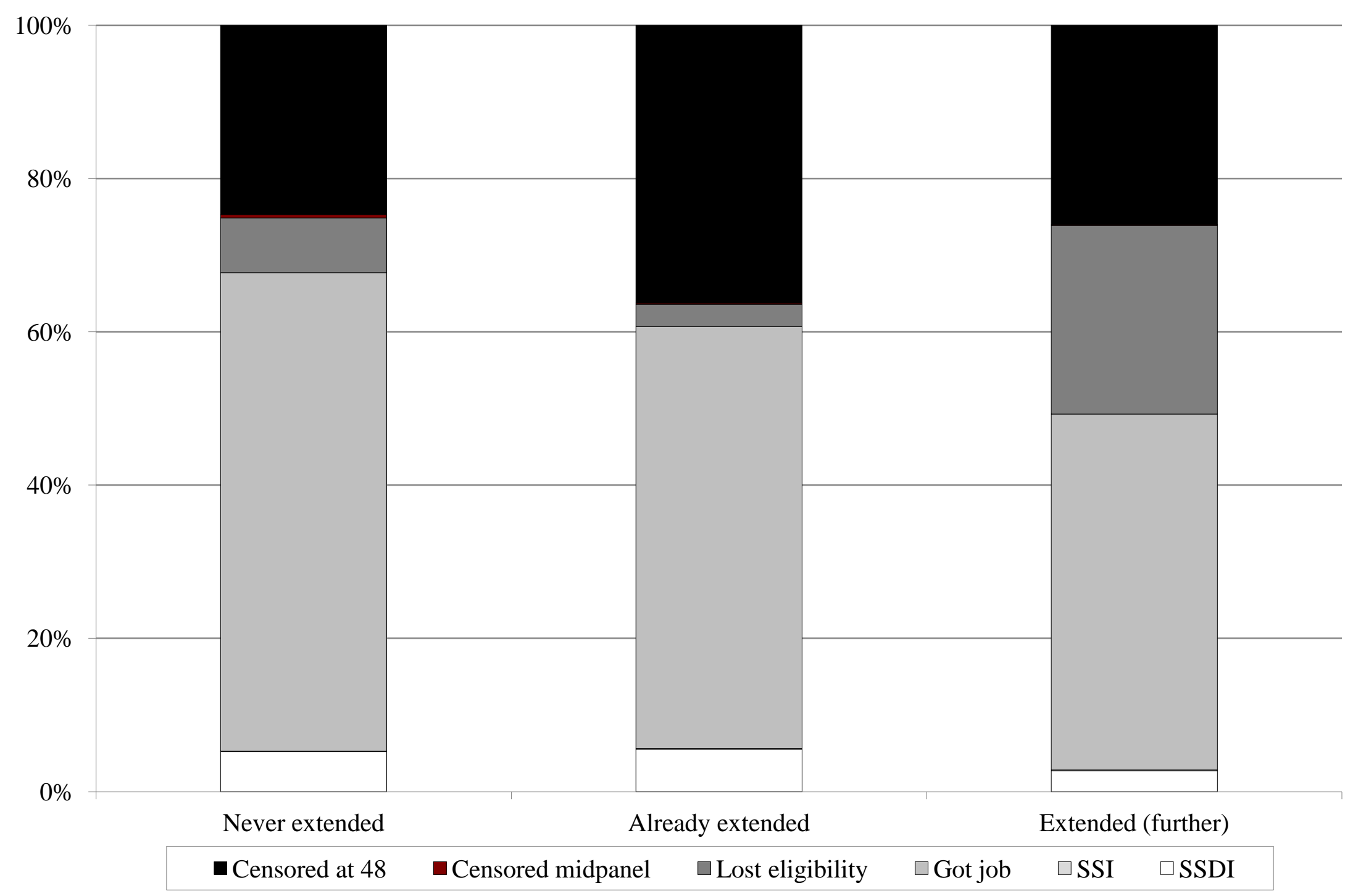

Source: Author's calculations from the Survey of Income and Program Participation Gold Standard File. 
Figure 4a. Predicted Hazard to SSDI Application, by Remaining UI Eligibility, no UI Extension

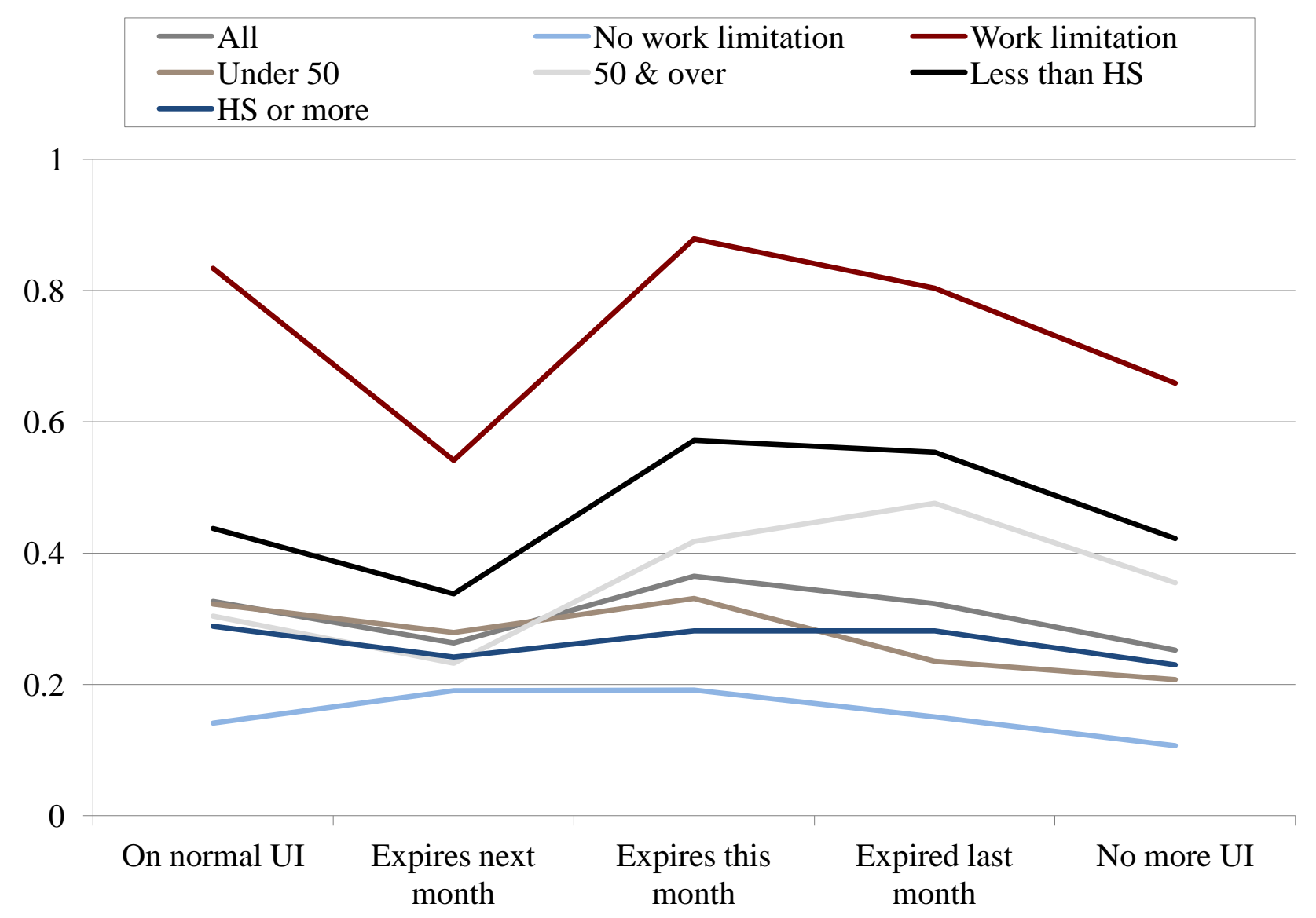

Source: Author's estimates from the Survey of Income and Program Participation Gold Standard File. 
Figure 4b. Predicted Hazard to SSDI Application, by Remaining UI Eligibility, UI Extended

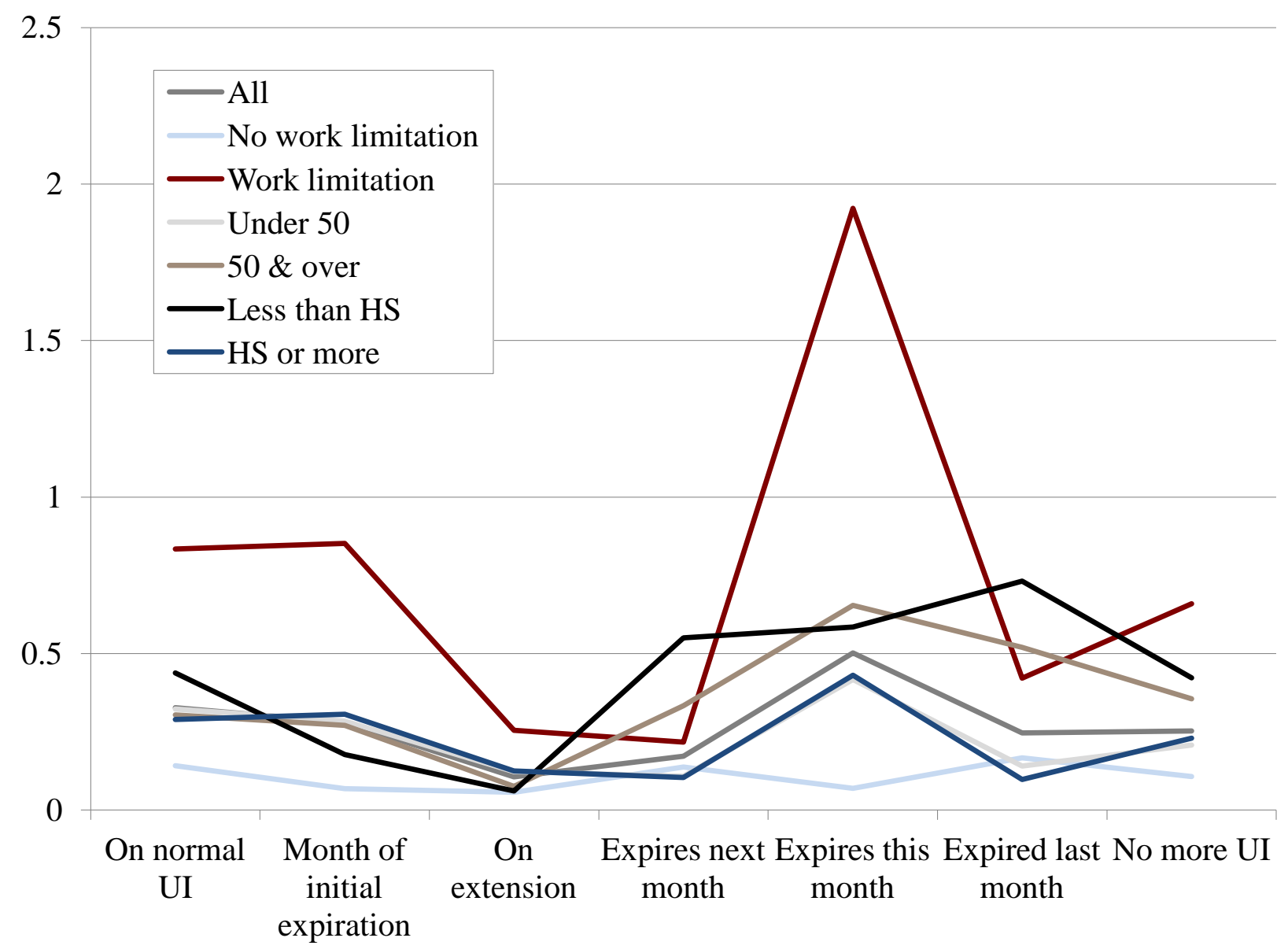

Source: Author's estimates from the Survey of Income and Program Participation Gold Standard File. 
Table 1. Refining the Sample

\begin{tabular}{lc}
\hline Refinement & Remaining sample \\
\hline Total sample in 1990-2004 SIPP panels & 704,510 \\
Age 25 to 64 & 367,597 \\
Non-missing work status & 295,927 \\
Experienced a job loss during SIPP & 58,323 \\
Matched successfully to SSA & 38,935 \\
Living in identifiable state & 35,257 \\
Filing date not the same as job loss date & 35,059 \\
Eligible for UI & 34,496 \\
Eligible for SSDI and/or SSI & 29,869 \\
\hline
\end{tabular}

Source: Author’s calculations from the Survey of Income and Program Participation Gold Standard File.

Table 2. Timing of Disability Application Relative to Unemployment Insurance Exhaustion

\begin{tabular}{lcccc}
\hline Month & All & Never extended & Already extended & Extended (further) \\
\hline$>2$ mo before UI ends & 114.8 & 85.8 & 29.1 & 11.0 \\
1-2 mo before UI ends & 78.9 & 57.8 & 18.7 & 6.2 \\
Month UI ends & 89.7 & 60.0 & 22.0 & 10.1 \\
1-2 mo after UI ends & 62.4 & 42.2 & 14.5 & 6.6 \\
3-6 mo after UI ends & 46.8 & 30.0 & 10.4 & 6.4 \\
7-12 mo after UI ends & 38.7 & 23.6 & 10.4 & 4.6 \\
13-24 mo after UI & 32.6 & 19.2 & 7.1 & 6.3 \\
ends & 24.6 & 14.5 & 5.1 & 5.0 \\
25-48 mo after UI & & & & \\
ends & & & & \\
\hline
\end{tabular}

Note: Figures are applications in the average month over the given time period.

Source: Author's calculations from the Survey of Income and Program Participation Gold Standard File. 
Table 3. Multinomial Logit Regression Results for SSDI Application or Job-Finding

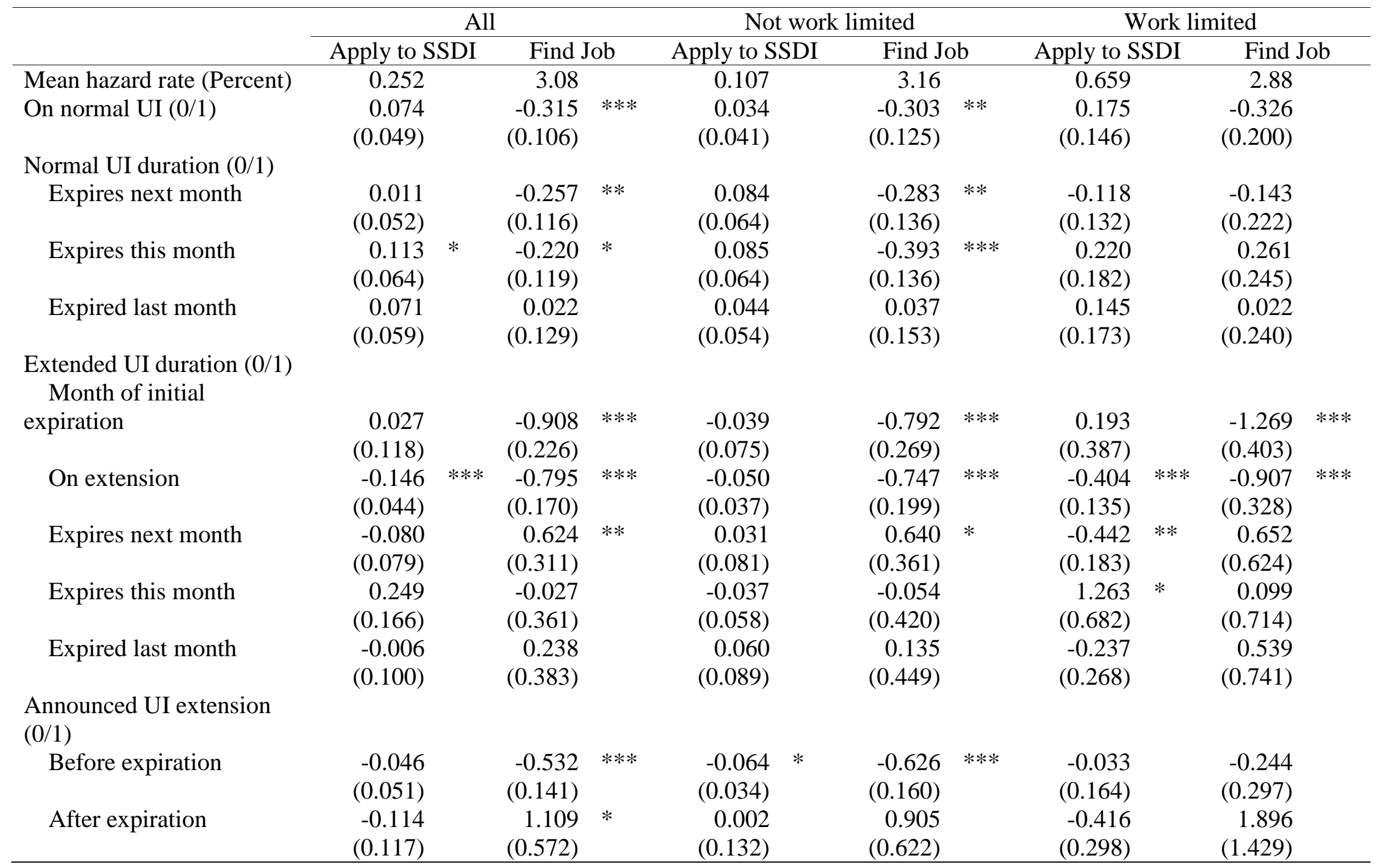


Table 3. Multinomial Logit Regression Results for SSDI Application or Job-Finding (cont'd)

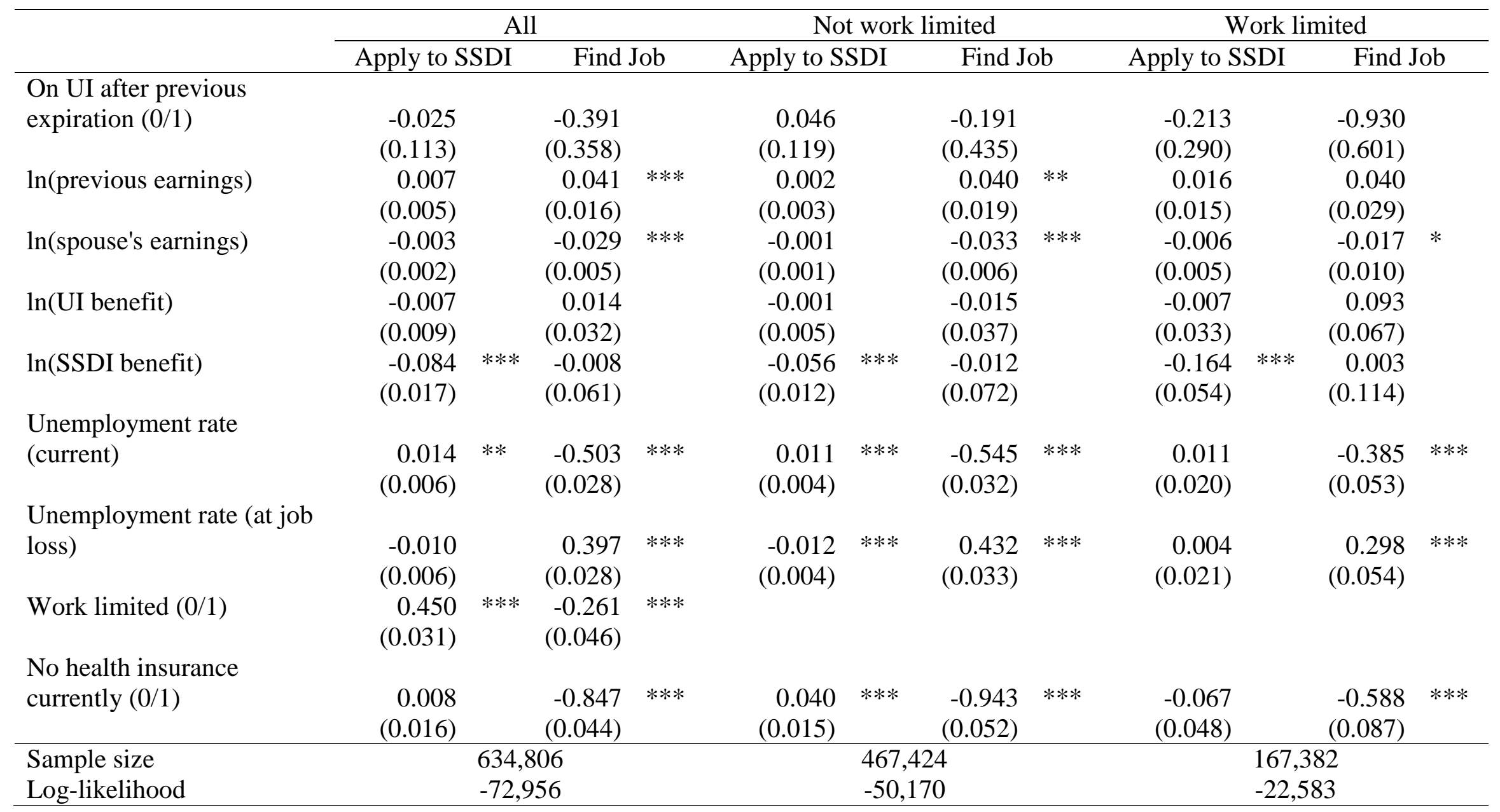

Note: For each variable, the table reports the marginal effect and its standard error (in parentheses); both parameter estimates are multiplied by 100 . All specifications also include demographic variables and month-since-separation fixed effects.

*** - Significantly different from zero at the 99 percent confidence level ** - 95 percent confidence level * 90 percent confidence level Source: Author’s estimates from the Survey of Income and Program Participation Gold Standard File. 
Table 4. Multinomial Logit Regression Results for Allowed SSDI Application, Job-Finding, or Denied SSDI Application

\begin{tabular}{|c|c|c|c|c|c|c|}
\hline \multirow{2}{*}{ Mean hazard rate (percent) } & \multicolumn{2}{|c|}{ SSDI allowed } & \multicolumn{2}{|l|}{ Find job } & \multicolumn{2}{|c|}{ SSDI denied } \\
\hline & 0.115 & & 3.08 & & 0.138 & \\
\hline \multirow[t]{2}{*}{ On normal UI (0/1) } & 0.049 & & -0.315 & $* * *$ & 0.033 & \\
\hline & $(0.037)$ & & $(0.106)$ & & $(0.034)$ & \\
\hline \multicolumn{7}{|l|}{ Normal UI duration (0/1) } \\
\hline \multirow{2}{*}{ Expires next month } & 0.042 & & -0.257 & $* *$ & -0.018 & \\
\hline & $(0.046)$ & & $(0.116)$ & & $(0.032)$ & \\
\hline \multirow[t]{2}{*}{ Expires this month } & 0.099 & $*$ & -0.220 & $*$ & 0.034 & \\
\hline & $(0.058)$ & & $(0.119)$ & & $(0.040)$ & \\
\hline \multirow[t]{2}{*}{ Expired last month } & 0.097 & $*$ & 0.022 & & -0.004 & \\
\hline & $(0.056)$ & & $(0.129)$ & & $(0.035)$ & \\
\hline \multicolumn{7}{|l|}{ Extended UI duration (0/1) } \\
\hline \multirow[t]{2}{*}{ Month of initial expiration } & -0.017 & & -0.908 & $* * *$ & 0.038 & \\
\hline & $(0.077)$ & & $(0.226)$ & & $(0.089)$ & \\
\hline \multirow[t]{2}{*}{ On extension } & -0.071 & $* *$ & -0.795 & $* * *$ & -0.075 & $* *$ \\
\hline & $(0.030)$ & & $(0.170)$ & & $(0.033)$ & \\
\hline \multirow[t]{2}{*}{ Expires next month } & 0.025 & & 0.623 & $* *$ & -0.090 & $* *$ \\
\hline & $(0.079)$ & & $(0.311)$ & & $(0.041)$ & \\
\hline \multirow[t]{2}{*}{ Expires this month } & 0.044 & & -0.026 & & 0.207 & \\
\hline & $(0.094)$ & & $(0.361)$ & & $(0.139)$ & \\
\hline \multirow[t]{2}{*}{ Expired last month } & -0.085 & $* *$ & 0.239 & & 0.079 & \\
\hline & $(0.037)$ & & $(0.383)$ & & $(0.094)$ & \\
\hline \multicolumn{7}{|l|}{ Announced UI extension (0/1) } \\
\hline \multirow[t]{2}{*}{ Before expiration } & -0.002 & & -0.532 & $* * *$ & -0.052 & \\
\hline & $(0.035)$ & & $(0.141)$ & & $(0.036)$ & \\
\hline \multirow[t]{2}{*}{ After expiration } & -0.029 & & 1.109 & $*$ & -0.080 & \\
\hline & $(0.105)$ & & $(0.572)$ & & $(0.070)$ & \\
\hline \multirow{3}{*}{$\begin{array}{l}\text { On UI after previous expiration } \\
(0 / 1)\end{array}$} & & & & & & \\
\hline & -0.007 & & -0.391 & & -0.018 & \\
\hline & $(0.085)$ & & $(0.358)$ & & $(0.077)$ & \\
\hline \multirow[t]{2}{*}{$\ln$ (previous earnings) } & 0.010 & *** & 0.041 & $* * *$ & -0.001 & \\
\hline & $(0.004)$ & & $(0.016)$ & & $(0.003)$ & \\
\hline \multirow[t]{2}{*}{ ln(spouse's earnings) } & -0.001 & & -0.029 & $* * *$ & -0.001 & \\
\hline & $(0.001)$ & & $(0.005)$ & & $(0.001)$ & \\
\hline \multirow[t]{2}{*}{$\ln (\mathrm{UI}$ benefit) } & -0.007 & & 0.014 & & -0.002 & \\
\hline & $(0.007)$ & & $(0.032)$ & & $(0.006)$ & \\
\hline \multirow[t]{2}{*}{$\ln ($ SSDI benefit) } & -0.026 & $* *$ & -0.008 & & -0.060 & $* * *$ \\
\hline & $(0.012)$ & & $(0.061)$ & & $(0.012)$ & \\
\hline \multirow[t]{2}{*}{ Unemployment rate (current) } & 0.006 & & -0.503 & $* * *$ & 0.008 & $* *$ \\
\hline & $(0.004)$ & & $(0.028)$ & & $(0.004)$ & \\
\hline Unemployment rate (at job loss) & -0.002 & & 0.397 & $* * *$ & -0.008 & * \\
\hline & $(0.004)$ & & $(0.028)$ & & $(0.004)$ & \\
\hline Work limited $(0 / 1)$ & 0.206 & $* * *$ & -0.261 & $* * *$ & 0.246 & $* * *$ \\
\hline & $(0.022)$ & & $(0.046)$ & & $(0.023)$ & \\
\hline
\end{tabular}


Table 4. Multinomial Logit Regression Results for Allowed SSDI Application, Job-Finding, or Denied SSDI Application (cont'd)

\begin{tabular}{|c|c|c|c|}
\hline & SSDI allowed & Find job & SSDI denied \\
\hline No health insurance currently $(0 / 1)$ & $\begin{array}{r}-0.020 * \\
(0.010)\end{array}$ & $\begin{array}{rl}-0.847 & * * * \\
(0.044) & \end{array}$ & $\begin{array}{rl}0.028 & * * \\
(0.013) & \end{array}$ \\
\hline $\begin{array}{l}\text { Sample size } \\
\text { Log-likelihood }\end{array}$ & & $\begin{array}{l}634,806 \\
-73,916\end{array}$ & \\
\hline
\end{tabular}

Note: For each variable, the table reports the marginal effect and its standard error (in parentheses); both parameter estimates are multiplied by 100 . All specifications also include demographic variables and month-since-separation fixed effects.

*** - Significantly different from zero at the 99 percent confidence level $* *$ - 95 percent confidence level * - 90 percent confidence level

Source: Author’s estimates from the Survey of Income and Program Participation Gold Standard File. 
Table 5. Estimated Effect of New, Ongoing, and Phased-Out Extensions on SSDI Application and Allowance Rates

\begin{tabular}{|c|c|c|c|c|}
\hline \multirow[b]{2}{*}{12 months before extension $(0 / 1)$} & \multicolumn{2}{|c|}{ Application rate } & \multicolumn{2}{|c|}{ Allowance rate } \\
\hline & $\begin{array}{c}-0.028 \\
(0.005)\end{array}$ & $* * *$ & & \\
\hline $\begin{array}{l}12 \text { months before extension, lagged } 4 \text { months } \\
(0 / 1)\end{array}$ & & & 0.673 & $* *$ \\
\hline & & & $(0.306)$ & \\
\hline First months of extension $(0 / 1)$ & $\begin{array}{l}-0.026 \\
(0.008)\end{array}$ & $* * *$ & & \\
\hline First months of extension, lagged 4 months $(0 / 1)$ & & & $\begin{array}{c}1.217 \\
(0.419)\end{array}$ & $* * *$ \\
\hline Ongoing extension $(0 / 1)$ & $\begin{array}{c}0.023 \\
(0.012)\end{array}$ & $* *$ & & \\
\hline Ongoing extension, lagged 4 months (0/1) & & & $\begin{array}{c}0.871 \\
(0.426)\end{array}$ & $* *$ \\
\hline Extension phase-Out $(0 / 1)$ & $\begin{array}{c}0.057 \\
(0.013)\end{array}$ & $* * *$ & & \\
\hline Extension phase-Out, lagged 4 months (0/1) & & & $\begin{array}{c}0.665 \\
(0.406)\end{array}$ & \\
\hline State unemployment rate & $\begin{array}{c}0.025 \\
(0.005)\end{array}$ & $* * *$ & & \\
\hline State unemployment rate 6 months ago & & & $\begin{array}{c}-0.226 \\
(0.172)\end{array}$ & \\
\hline Proportion at maximum duration & $\begin{array}{c}0.004 \\
(0.003)\end{array}$ & & & \\
\hline Proportion at max duration 4 months ago & & & $\begin{array}{l}-0.817 \\
(0.154)\end{array}$ & $* * *$ \\
\hline Constant & $\begin{array}{c}0.233 \\
(0.044)\end{array}$ & $* * *$ & $\begin{array}{c}52.48 \\
(1.647)\end{array}$ & $* * *$ \\
\hline $\mathrm{R}^{2}$ & 0.849 & & 0.712 & \\
\hline Sample size & 6885 & & 6885 & \\
\hline
\end{tabular}

Note: Regressions include linear and quadratic time trends and month and state fixed effects. Standard errors in parentheses.

*** - Significantly different from zero at the 99 percent confidence level ** - 95 percent confidence level * 90 percent confidence level

Source: Author’s estimates from the Survey of Income and Program Participation Gold Standard File. 
Table 6. Expected Cost of 13- or 26-week UI Extensions

\begin{tabular}{|c|c|c|c|c|c|c|c|}
\hline \multirow{3}{*}{$\begin{array}{l}\text { Extension weeks } \\
\end{array}$} & & \multicolumn{6}{|c|}{ Full sample } \\
\hline & & \multicolumn{3}{|c|}{ Per-person cost (\$) } & \multicolumn{3}{|c|}{ Percent change } \\
\hline & & 0 wks & 13 wks & 26 wks & 0 to 13 & 0 to 26 & 13 to 26 \\
\hline \multirow[t]{3}{*}{ Total cost } & Mean & 2,442 & 2,665 & 2,973 & 10.7 & 25.4 & 13.3 \\
\hline & SD & $(1,719.9)$ & $(1,783.3)$ & $(1,892.7)$ & (8.2) & $(15.3)$ & (11.4) \\
\hline & Median & $\{2,067\}$ & $\{2,314\}$ & $\{2,639\}$ & $\{10.5\}$ & $\{25.1\}$ & $\{12.3\}$ \\
\hline \multirow[t]{3}{*}{ UI } & Mean & 1,501 & 1,757 & 2,080 & 18.2 & 42.2 & 20.7 \\
\hline & SD & (940.4) & $(1,069.9)$ & $(1,220.3)$ & $(11.1)$ & (20.4) & $(17.8)$ \\
\hline & Median & $\{1,417\}$ & $\{1,660\}$ & $\{1,987\}$ & $\{17.8\}$ & $\{41\}$ & $\{18.4\}$ \\
\hline \multirow[t]{3}{*}{ SSDI and Medicare } & Mean & 1,065 & 908 & 892 & -3.3 & -4.8 & -1.5 \\
\hline & & (970.4) & (936.2) & (919.7) & (3.3) & $(4.9)$ & (5.8) \\
\hline & Median & $\{500\}$ & $\{484\}$ & $\{476\}$ & $\{-6.9\}$ & $\{-10.3\}$ & $\{-3.8\}$ \\
\hline \multirow{3}{*}{\multicolumn{2}{|c|}{ Sample size }} & \multicolumn{6}{|c|}{34,152} \\
\hline & & \multicolumn{6}{|c|}{ Work limited } \\
\hline & & \multicolumn{3}{|c|}{ Per-person cost (\$) } & \multicolumn{3}{|c|}{ Percent change } \\
\hline Extension weeks & & 0 wks & 13 wks & 26 wks & 0 to 13 & 0 to 26 & 13 to 26 \\
\hline \multirow[t]{3}{*}{ Total cost } & Mean & 3,829 & 4,003 & 4,293 & 5.3 & 14.0 & 8.2 \\
\hline & SD & $(2,270.7)$ & $(2,324.2)$ & $(2,433.8)$ & (5.8) & $(11.0)$ & (8.1) \\
\hline & Median & $\{3,348\}$ & $\{3,540\}$ & $\{3,821\}$ & $\{4.7\}$ & $\{12.4\}$ & $\{7.1\}$ \\
\hline \multirow[t]{3}{*}{ UI } & Mean & 1,451 & 1,710 & 2,040 & 19.1 & 44.6 & 21.9 \\
\hline & SD & (948.9) & $(1,083.6)$ & $(1,240.4)$ & $(11.4)$ & $(21.2)$ & (19.1) \\
\hline & Median & $\{1,336\}$ & $\{1,575\}$ & $\{1,901\}$ & $\{18.8\}$ & $\{43.8\}$ & $\{19.7\}$ \\
\hline \multirow{3}{*}{ SSDI and Medicare } & Mean & 2,377 & 2,294 & 2,253 & -3.4 & -4.9 & -1.5 \\
\hline & & $(1,350.3)$ & $(1,302.9)$ & $(1,280.1)$ & (3.3) & $(5.0)$ & (5.9) \\
\hline & Median & $\{2,180\}$ & $\{2,113\}$ & $\{2,075\}$ & $\{-7.3\}$ & $\{-10.6\}$ & $\{-3.9\}$ \\
\hline Sample size & & \multicolumn{6}{|c|}{9,298} \\
\hline
\end{tabular}

Source: Author's estimates from the Survey of Income and Program Participation Gold Standard File. 
Table A1. Summary Statistics for Individual-Level Sample

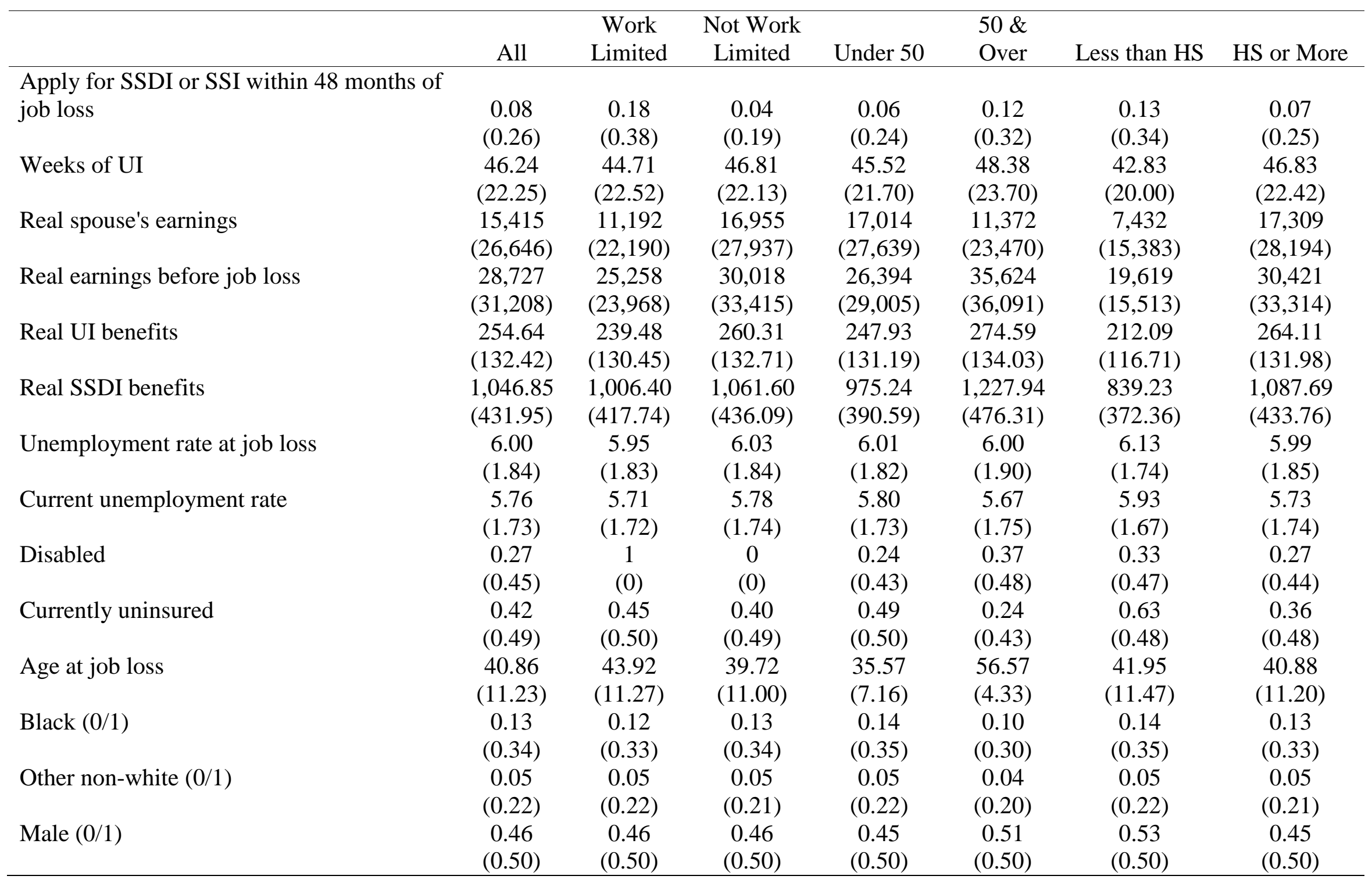


Table A1. Summary Statistics for Individual-Level Sample (cont'd)

\begin{tabular}{|c|c|c|c|c|c|c|c|}
\hline \multirow{3}{*}{ High school graduate only (0/1) } & \multirow{2}{*}{\multicolumn{2}{|c|}{$\begin{array}{c}\text { Work } \\
\text { Limited }\end{array}$}} & \multirow{2}{*}{$\begin{array}{l}\text { Not Work } \\
\text { Limited }\end{array}$} & \multicolumn{3}{|c|}{$50 \&$} & \multirow[b]{2}{*}{ HS or More } \\
\hline & & & & Under 50 & Over & Less than HS & \\
\hline & $(0.46)$ & $(0.47)$ & $(0.46)$ & $(0.46)$ & $(0.47)$ & $(0.00)$ & $(0.49)$ \\
\hline Some college $(0 / 1)$ & $(0.46)$ & $(0.47)$ & $(0.45)$ & $(0.46)$ & $(0.45)$ & $(0.00)$ & $(0.48)$ \\
\hline \multirow[t]{2}{*}{ College degree (0/1) } & 0.20 & 0.13 & 0.22 & 0.19 & 0.21 & 0.00 & 0.24 \\
\hline & $(0.40)$ & $(0.34)$ & $(0.42)$ & $(0.39)$ & $(0.41)$ & $(0.00)$ & $(0.43)$ \\
\hline \multirow[t]{2}{*}{ Married (0/1) } & 0.61 & 0.57 & 0.62 & 0.58 & 0.69 & 0.61 & 0.61 \\
\hline & $(0.49)$ & $(0.50)$ & $(0.49)$ & $(0.49)$ & $(0.46)$ & $(0.49)$ & $(0.49)$ \\
\hline \multirow[t]{2}{*}{ Foreign-born (0/1) } & 0.10 & 0.09 & 0.10 & 0.10 & 0.09 & 0.26 & 0.08 \\
\hline & $(0.30)$ & $(0.28)$ & $(0.31)$ & $(0.30)$ & $(0.28)$ & $(0.44)$ & $(0.27)$ \\
\hline \multirow[t]{2}{*}{ 2nd wealth quintile $(0 / 1)$} & 0.20 & 0.21 & 0.20 & 0.23 & 0.11 & 0.27 & 0.19 \\
\hline & $(0.40)$ & $(0.40)$ & $(0.40)$ & $(0.42)$ & $(0.31)$ & $(0.44)$ & $(0.40)$ \\
\hline \multirow[t]{2}{*}{ 5th wealth quintile $(0 / 1)$} & 0.15 & 0.13 & 0.15 & 0.10 & 0.30 & 0.05 & 0.17 \\
\hline & $(0.35)$ & $(0.33)$ & $(0.36)$ & $(0.29)$ & $(0.46)$ & $(0.21)$ & $(0.37)$ \\
\hline \multirow[t]{2}{*}{ Wealth N/A (0/1) } & 0.05 & 0.04 & 0.06 & 0.06 & 0.04 & 0.04 & 0.04 \\
\hline & $(0.23)$ & $(0.19)$ & $(0.24)$ & $(0.23)$ & $(0.20)$ & $(0.20)$ & $(0.19)$ \\
\hline Unique individuals & 29,887 & 8,013 & 21,874 & 22,178 & 7,709 & 3,844 & 24,394 \\
\hline Person-spells & 34,152 & 9,298 & 24,854 & 25,548 & 8,604 & 4,605 & 27,790 \\
\hline Person-years & 84,179 & 22,497 & 61,682 & 60,326 & 23,853 & 11,689 & 67,194 \\
\hline Person-months & 668,958 & 176,680 & 492,278 & 468,024 & 200,934 & 92,943 & 530,198 \\
\hline
\end{tabular}

Note: Standard deviations in parentheses.

Source: Author's calculations from the Survey of Income and Program Participation Gold Standard File. 
Table A2. Cost of Medicare per Disabled Enrollee

\begin{tabular}{lccc}
\hline Year & Disabled enrollees (millions) & Disabled Medicare program payments (\$ thousands) & Cost per disabled enrollee \\
\hline 1990 & 3,252 & 11,799 & $3,628.23$ \\
1991 & 3,477 & 12,828 & $3,689.65$ \\
1992 & 3,702 & 14,469 & $3,908.96$ \\
1993 & 3,926 & 15,894 & $4,048.14$ \\
1994 & 4,151 & 18,835 & $4,537.46$ \\
1995 & 4,409 & 21,029 & $4,769.56$ \\
1996 & 4,654 & 22,577 & $4,851.10$ \\
1997 & 4,829 & 23,768 & $4,921.93$ \\
1998 & 5,041 & 23,746 & $4,710.57$ \\
1999 & 5,219 & 24,262 & $4,648.78$ \\
2000 & 5,371 & 25,773 & $4,798.55$ \\
2001 & 5,567 & 29,680 & $5,331.42$ \\
2002 & 5,805 & 33,108 & $5,703.36$ \\
2003 & 6,077 & 37,095 & $6,104.16$ \\
2004 & 6,401 & 42,085 & $6,574.75$ \\
2005 & 6,723 & 46,550 & $6,923.99$ \\
2006 & 7,022 & 48,204 & $6,864.66$ \\
2007 & 7,297 & 50,697 & $6,947.44$ \\
2008 & 7,516 & 54,018 & $7,187.25$ \\
2009 & 7,755 & 59,462 & $7,667.30$ \\
\hline
\end{tabular}

Source: CMS Medicare and Medicaid Statistical Supplement. 
Table A3. Multinomial Logit Regression Results for SSDI Application or Job-Finding, by Age at Job Separation and Education

\begin{tabular}{|c|c|c|c|c|c|c|c|c|c|c|c|c|c|c|c|c|}
\hline & \multicolumn{4}{|c|}{ Under 50} & \multicolumn{4}{|c|}{ Over 50} & \multicolumn{4}{|c|}{ Less than HS } & \multicolumn{4}{|c|}{ HS or more } \\
\hline & \multicolumn{2}{|c|}{ Apply to SSDI } & \multicolumn{2}{|c|}{ Find job } & \multicolumn{2}{|c|}{ Apply to SSDI } & \multicolumn{2}{|c|}{ Find job } & \multicolumn{2}{|c|}{ Apply to SSDI } & \multicolumn{2}{|c|}{ Find job } & \multicolumn{2}{|c|}{ Apply to SSDI } & \multicolumn{2}{|c|}{ Find job } \\
\hline Mean hazard rate (percent) & 0.208 & & 3.58 & & 0.355 & & 1.93 & & 0.422 & & 2.88 & & 0.23 & & 3.24 & \\
\hline On normal UI $(0 / 1)$ & $\begin{array}{r}0.115 \\
(0.060)\end{array}$ & $*$ & $\begin{array}{r}-0.379 \\
(0.135)\end{array}$ & $* * *$ & $\begin{array}{r}-0.051 \\
(0.088)\end{array}$ & & $\begin{array}{r}-0.191 \\
(0.160)\end{array}$ & & $\begin{array}{r}0.015 \\
(0.142)\end{array}$ & & $\begin{array}{r}0.161 \\
(0.277)\end{array}$ & & $\begin{array}{r}0.059 \\
(0.053)\end{array}$ & & $\begin{array}{r}-0.227 \\
(0.127)\end{array}$ & $*$ \\
\hline \multicolumn{17}{|l|}{ Normal UI duration $(0 / 1)$} \\
\hline Expires next month & $\begin{array}{r}0.071 \\
(0.069)\end{array}$ & & $\begin{array}{r}-0.259 \\
(0.149)\end{array}$ & $*$ & $\begin{array}{r}-0.123 \\
(0.078)\end{array}$ & & $\begin{array}{r}-0.265 \\
(0.169)\end{array}$ & & $\begin{array}{r}-0.084 \\
(0.138)\end{array}$ & & $\begin{array}{r}-0.622 \\
(0.251)\end{array}$ & $* *$ & $\begin{array}{r}0.012 \\
(0.057)\end{array}$ & & $\begin{array}{r}-0.213 \\
(0.139)\end{array}$ & \\
\hline Expires this month & $\begin{array}{r}0.123 \\
(0.076)\end{array}$ & & $\begin{array}{r}-0.281 \\
(0.151)\end{array}$ & $*$ & $\begin{array}{r}0.062 \\
(0.117)\end{array}$ & & $\begin{array}{r}-0.056 \\
(0.187)\end{array}$ & & $\begin{array}{r}0.150 \\
(0.190)\end{array}$ & & $\begin{array}{r}-0.001 \\
(0.300)\end{array}$ & & $\begin{array}{r}0.052 \\
(0.063)\end{array}$ & & $\begin{array}{r}-0.160 \\
(0.143)\end{array}$ & \\
\hline Expired last month & $\begin{array}{r}0.028 \\
(0.061)\end{array}$ & & $\begin{array}{r}-0.084 \\
(0.162)\end{array}$ & & $\begin{array}{r}0.121 \\
(0.129)\end{array}$ & & $\begin{array}{r}0.282 \\
(0.212)\end{array}$ & & $\begin{array}{r}0.132 \\
(0.189)\end{array}$ & & $\begin{array}{r}0.304 \\
(0.333)\end{array}$ & & $\begin{array}{r}0.052 \\
(0.064)\end{array}$ & & $\begin{array}{r}-0.018 \\
(0.151)\end{array}$ & \\
\hline \multicolumn{17}{|l|}{ Extended UI duration $(0 / 1)$} \\
\hline Month of initial expiration & $\begin{array}{r}0.076 \\
(0.155)\end{array}$ & & $\begin{array}{r}-1.057 \\
(0.286)\end{array}$ & $* * *$ & $\begin{array}{r}-0.085 \\
(0.182)\end{array}$ & & $\begin{array}{r}-0.589 \\
(0.347)\end{array}$ & $*$ & $\begin{array}{r}-0.245 \\
(0.207)\end{array}$ & & $\begin{array}{r}-1.188 \\
(0.474)\end{array}$ & $* *$ & $\begin{array}{r}0.076 \\
(0.140)\end{array}$ & & $\begin{array}{r}-0.795 \\
(0.278)\end{array}$ & $* * *$ \\
\hline On extension & $\begin{array}{r}-0.085 \\
(0.058)\end{array}$ & & $\begin{array}{r}-0.928 \\
(0.215)\end{array}$ & $* * *$ & $\begin{array}{r}-0.280 \\
(0.068)\end{array}$ & $* * *$ & $\begin{array}{r}-0.427 \\
(0.275)\end{array}$ & & $\begin{array}{r}-0.361 \\
(0.088)\end{array}$ & $* * *$ & $\begin{array}{r}-1.463 \\
(0.321)\end{array}$ & $* * *$ & $\begin{array}{r}-0.105 \\
(0.055)\end{array}$ & $*$ & $\begin{array}{r}-0.666 \\
(0.206)\end{array}$ & $* * *$ \\
\hline Expires next month & $\begin{array}{r}-0.100 \\
(0.073)\end{array}$ & & $\begin{array}{r}0.626 \\
(0.392)\end{array}$ & & $\begin{array}{r}-0.022 \\
(0.207)\end{array}$ & & $\begin{array}{r}0.616 \\
(0.491)\end{array}$ & & $\begin{array}{r}0.128 \\
(0.351)\end{array}$ & & $\begin{array}{r}1.194 \\
(0.760)\end{array}$ & & $\begin{array}{r}-0.126 \\
(0.071)\end{array}$ & $*$ & $\begin{array}{r}0.709 \\
(0.375)\end{array}$ & $*$ \\
\hline Expires this month & $\begin{array}{r}0.210 \\
(0.178)\end{array}$ & & $\begin{array}{r}0.008 \\
(0.460)\end{array}$ & & $\begin{array}{r}0.298 \\
(0.354)\end{array}$ & & $\begin{array}{r}-0.144 \\
(0.535)\end{array}$ & & $\begin{array}{r}0.163 \\
(0.386)\end{array}$ & & $\begin{array}{r}-1.136 \\
(0.604)\end{array}$ & $*$ & $\begin{array}{r}0.201 \\
(0.188)\end{array}$ & & $\begin{array}{r}0.237 \\
(0.450)\end{array}$ & \\
\hline Expired last month & $\begin{array}{r}-0.068 \\
(0.089)\end{array}$ & & $\begin{array}{r}0.308 \\
(0.490)\end{array}$ & & $\begin{array}{r}0.164 \\
(0.273)\end{array}$ & & $\begin{array}{r}0.080 \\
(0.567)\end{array}$ & & $\begin{array}{r}0.309 \\
(0.387)\end{array}$ & & $\begin{array}{r}0.119 \\
(0.806)\end{array}$ & & $\begin{array}{r}-0.132 \\
(0.080)\end{array}$ & * & $\begin{array}{r}0.171 \\
(0.457)\end{array}$ & \\
\hline \multicolumn{17}{|l|}{ Announced UI extension (0/1) } \\
\hline Before expiration & $\begin{array}{r}0.016 \\
(0.069)\end{array}$ & & $\begin{array}{r}-0.645 \\
(0.180)\end{array}$ & $* * *$ & $\begin{array}{r}-0.157 \\
(0.083)\end{array}$ & $*$ & $\begin{array}{r}-0.291 \\
(0.207)\end{array}$ & & $\begin{array}{r}-0.352 \\
(0.095)\end{array}$ & $* * *$ & $\begin{array}{c}-1.174 \\
(0.329)\end{array}$ & $* * *$ & $\begin{array}{r}0.007 \\
(0.060)\end{array}$ & & $\begin{array}{r}-0.507 \\
(0.162)\end{array}$ & $* * *$ \\
\hline After expiration & $\begin{array}{r}-0.147 \\
(0.077)\end{array}$ & $*$ & $\begin{array}{r}1.179 \\
(0.708)\end{array}$ & $*$ & $\begin{array}{r}0.192 \\
(0.633)\end{array}$ & & $\begin{array}{r}1.058 \\
(1.019)\end{array}$ & & $\begin{array}{r}0.122 \\
(0.686)\end{array}$ & & $\begin{array}{r}0.696 \\
(1.192)\end{array}$ & & $\begin{array}{r}-0.158 \\
(0.091)\end{array}$ & * & $\begin{array}{r}1.211 \\
(0.708)\end{array}$ & $*$ \\
\hline On UI after previous expiration $(0 / 1)$ & $\begin{array}{r}0.155 \\
(0.198)\end{array}$ & & $\begin{array}{r}-0.294 \\
(0.469)\end{array}$ & & $\begin{array}{r}-0.302 \\
(0.082)\end{array}$ & $* * *$ & $\begin{array}{r}-0.683 \\
(0.446)\end{array}$ & & $\begin{array}{r}-0.194 \\
(0.235)\end{array}$ & & $\begin{array}{r}0.040 \\
(0.876)\end{array}$ & & $\begin{array}{r}0.091 \\
(0.186)\end{array}$ & & $\begin{array}{r}-0.559 \\
(0.418)\end{array}$ & \\
\hline $\ln$ (previous earnings) & $\begin{array}{r}0.002 \\
(0.005)\end{array}$ & & $\begin{array}{r}0.061 \\
(0.020)\end{array}$ & $* * *$ & $\begin{array}{r}0.019 \\
(0.012)\end{array}$ & & $\begin{array}{r}-0.001 \\
(0.023)\end{array}$ & & $\begin{array}{r}0.001 \\
(0.017)\end{array}$ & & $\begin{array}{r}0.009 \\
(0.044)\end{array}$ & & $\begin{array}{r}0.007 \\
(0.005)\end{array}$ & & $\begin{array}{r}0.052 \\
(0.019)\end{array}$ & $* * *$ \\
\hline ln(spouse's earnings) & $\begin{array}{r}-0.002 \\
(0.002)\end{array}$ & & $\begin{array}{r}-0.046 \\
(0.007)\end{array}$ & $* * *$ & $\begin{array}{r}-0.006 \\
(0.004)\end{array}$ & & $\begin{array}{r}0.005 \\
(0.007)\end{array}$ & & $\begin{array}{r}-0.003 \\
(0.006)\end{array}$ & & $\begin{array}{r}-0.065 \\
(0.014)\end{array}$ & $* * *$ & $\begin{array}{r}-0.002 \\
(0.002)\end{array}$ & & $\begin{array}{r}-0.026 \\
(0.006)\end{array}$ & $* * *$ \\
\hline
\end{tabular}


Table A3. Multinomial Logit Regression Results for SSDI Application or Job-Finding, by Age at Job Separation and Education (cont'd)

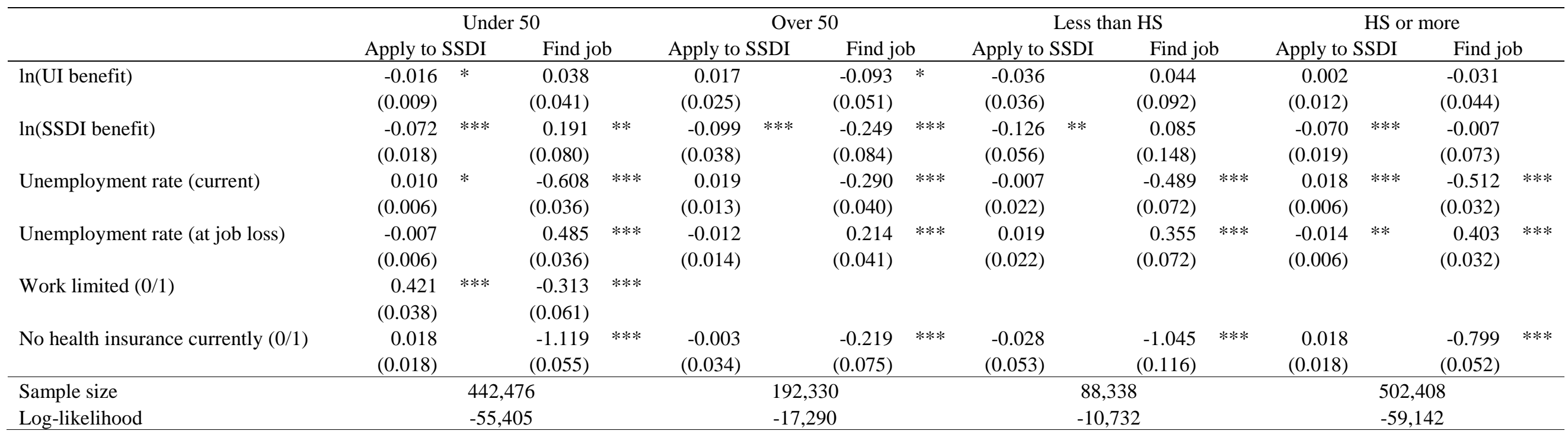

Note: For each variable, the table reports the marginal effect and its standard error (in parentheses); both parameter estimates are multiplied by 100 . All specifications also include demographic variables and month-since-separation fixed effects.

$* * *$ - Significantly different from zero at the 99 percent confidence level $* *$ - 95 percent confidence level $*$ - 90 percent confidence level

Source: Author's estimates from the Survey of Income and Program Participation Gold Standard File. 
Table A4. Multinomial Logit Regression Results for Allowed SSDI Application, Job-Finding, or Denied SSDI Application

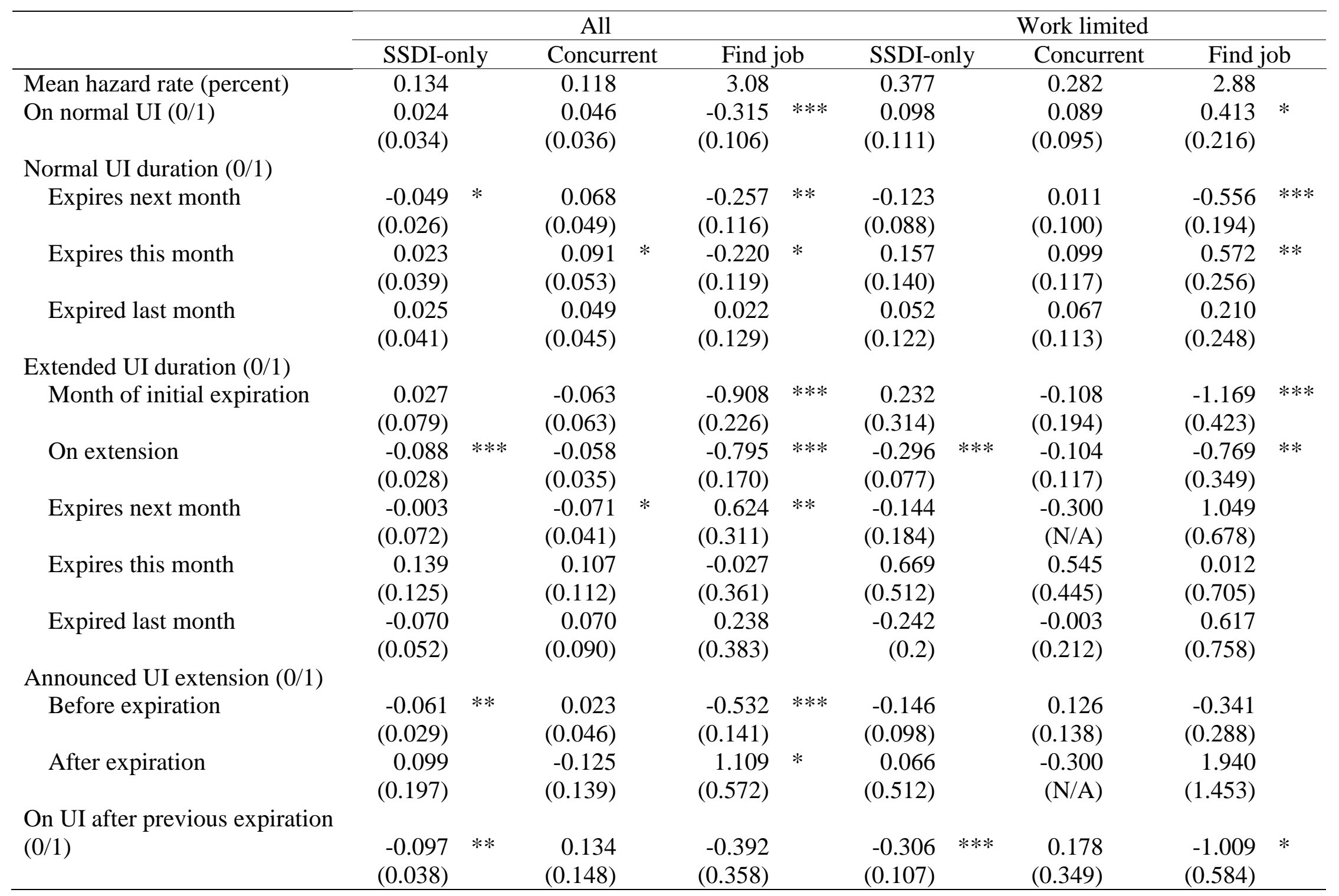


Table A4. Multinomial Logit Regression Results for Allowed SSDI Application, Job-Finding, or Denied SSDI Application (cont'd)

\begin{tabular}{|c|c|c|c|c|c|c|c|c|c|c|c|c|}
\hline \multirow{3}{*}{ ln(previous earnings) } & \multicolumn{6}{|c|}{ All } & \multicolumn{6}{|c|}{ Work limited } \\
\hline & \multicolumn{2}{|c|}{ SSDI-only } & \multicolumn{2}{|c|}{ Concurrent } & \multicolumn{2}{|c|}{ Find job } & \multicolumn{2}{|c|}{ SSDI-only } & \multicolumn{2}{|c|}{ Concurrent } & \multicolumn{2}{|c|}{ Find job } \\
\hline & 0.010 & $* *$ & -0.002 & & 0.041 & $* * *$ & 0.024 & & -0.007 & & 0.022 & \\
\hline & $(0.004)$ & & $(0.003)$ & & $(0.016)$ & & $(0.015)$ & & $(0.008)$ & & $(0.029)$ & \\
\hline \multirow[t]{2}{*}{$\ln$ (spouse's earnings) } & 0.000 & & -0.003 & $* *$ & -0.029 & $* * *$ & 0.000 & & -0.010 & $* *$ & -0.018 & $*$ \\
\hline & $(0.001)$ & & $(0.001)$ & & $(0.005)$ & & $(0.004)$ & & $(0.004)$ & & $(0.010)$ & \\
\hline \multirow{2}{*}{$\ln$ (UI benefit) } & 0.006 & & -0.009 & $*$ & 0.014 & & 0.047 & & -0.032 & $*$ & 0.082 & \\
\hline & $(0.008)$ & & $(0.005)$ & & $(0.032)$ & & $(0.032)$ & & $(0.017)$ & & $(0.068)$ & \\
\hline \multirow[t]{2}{*}{$\ln ($ SSDI benefit) } & 0.004 & & -0.079 & $* * *$ & -0.008 & & 0.008 & & -0.161 & $* * *$ & -0.005 & \\
\hline & $(0.014)$ & & $(0.010)$ & & $(0.061)$ & & $(0.046)$ & & $(0.032)$ & & $(0.114)$ & \\
\hline \multirow[t]{2}{*}{ Unemployment rate (current) } & 0.006 & & 0.008 & $* *$ & -0.503 & $* * *$ & 0.000 & & 0.011 & & -0.403 & $* * *$ \\
\hline & $(0.004)$ & & $(0.004)$ & & $(0.028)$ & & $(0.016)$ & & $(0.013)$ & & $(0.053)$ & \\
\hline \multicolumn{13}{|l|}{ Unemployment rate (at job } \\
\hline \multirow[t]{2}{*}{ loss) } & -0.003 & & -0.007 & & 0.397 & $* * *$ & 0.005 & & -0.001 & & 0.272 & $* * *$ \\
\hline & $(0.005)$ & & $(0.004)$ & & $(0.028)$ & & $(0.016)$ & & $(0.013)$ & & $(0.054)$ & \\
\hline \multirow[t]{2}{*}{ Work limited $(0 / 1)$} & 0.285 & $* * *$ & 0.169 & $* * *$ & -0.261 & $* * *$ & & & & & & \\
\hline & $(0.027)$ & & $(0.018)$ & & $(0.046)$ & & & & & & & \\
\hline \multirow{2}{*}{$\begin{array}{l}\text { No health insurance currently } \\
(0 / 1)\end{array}$} & & & & & & & & & & & & \\
\hline & $\begin{array}{r}-0.079 \\
(0.009)\end{array}$ & $* * *$ & $\begin{array}{r}0.087 \\
(0.016)\end{array}$ & $* * *$ & $\begin{array}{r}-0.847 \\
(0.044)\end{array}$ & $* * *$ & $\begin{array}{r}-0.257 \\
(0.026)\end{array}$ & $* * *$ & $\begin{array}{r}0.186 \\
(0.046)\end{array}$ & $* * *$ & $\begin{array}{r}-0.608 \\
(0.087)\end{array}$ & $* * *$ \\
\hline Sample size & \multicolumn{6}{|c|}{634,806} & \multicolumn{6}{|c|}{167,382} \\
\hline Log-likelihood & \multicolumn{6}{|c|}{$-73,646$} & \multicolumn{6}{|c|}{$-23,249$} \\
\hline
\end{tabular}

Note: For each variable, the table reports the marginal effect and its standard error (in parentheses); both parameter estimates are multiplied by 100. All specifications also include demographic variables and month-since-separation fixed effects.

*** - Significantly different from zero at the 99 percent confidence level ** - 95 percent confidence level * - 90 percent confidence level

Source: Author's estimates from the Survey of Income and Program Participation Gold Standard File. 


\section{RECENT WORKING PAPERS FROM THE}

\section{CENTER FOR RETIREMENT RESEARCH AT BOSTON COLLEGE}

Do Couples Self-Insure? The Effect of Informal Care on a Couple's Labor Supply

Norma B. Coe, Meghan Skira, and Courtney Harold Van Houtven, October 2011

How Prepared Are State and Local Workers for Retirement?

Alicia H. Munnell, Jean-Pierre Aubry, Josh Hurwitz, and Laura Quinby, October 2011

Social Security Reform and Male Labor Force Participation Around the World Jocelyn E. Finlay and Günther Fink, September 2011

Corporate Pension Plan Investments in Alternative Assets: Determinants and Consequences

Divya Anantharaman, August 2011

Social Security Reform and Male Labor Force Participation Around the World Jocelyn E. Finlay and Günther Fink, June 2011

An In-Depth Look into Intergenerational Flows

Oksana Leukhina and Marika Santoro, May 2011

Who Retires Early?

Henry J. Aaron and Jean Marie Callan, May 2011

The Potential Impact of the Great Recession on Future Retirement Incomes

Barbara A. Butrica, Richard W. Johnson, and Karen E. Smith, May 2011

Immigrant Diversity and Social Security: Recent patterns and Future Prospects

Melissa M. Favreault and Austin Nichols, May 2011

Why Aren't More Families Buying Life Insurance?

Matthew S. Chambers, Don E. Schlagenhauf, and Eric R. Young, March 2011

Changes in Firm Pension Policy: Trends Away From Traditional Defined Benefit Plans Kandice A. Kapinos, February 2011

Interdependent Durations in Joint Retirement

Bo Honoré and Áureo de Paula, February 2011

Health and Retirement Effects in a Collective Consumption Model of Elderly Households Arthur Lewbel and Shannon Seitz, February 2011

All working papers are available on the Center for Retirement Research website (http://crr.bc.edu) and can be requested by e-mail (crr@bc.edu) or phone (617-552-1762). 